\title{
On the Determinants of the Conjunction Fallacy: Probability Versus Inductive Confirmation
}

\author{
Katya Tentori \\ University of Trento
}

\author{
Vincenzo Crupi \\ University of Torino and Ludwig Maximilian University
}

\author{
Selena Russo \\ University of Trento
}

\begin{abstract}
Major recent interpretations of the conjunction fallacy postulate that people assess the probability of a conjunction according to (non-normative) averaging rules as applied to the constituents' probabilities or represent the conjunction fallacy as an effect of random error in the judgment process. In the present contribution, we contrast such accounts with a different reading of the phenomenon based on the notion of inductive confirmation as defined by contemporary Bayesian theorists. Averaging rule hypotheses along with the random error model and many other existing proposals are shown to all imply that conjunction fallacy rates would rise as the perceived probability of the added conjunct does. By contrast, our account predicts that the conjunction fallacy depends on the added conjunct being perceived as inductively confirmed. Four studies are reported in which the judged probability versus confirmation of the added conjunct have been systematically manipulated and dissociated. The results consistently favor a confirmation-theoretic account of the conjunction fallacy against competing views. Our proposal is also discussed in connection with related issues in the study of human inductive reasoning.
\end{abstract}

Keywords: conjunction fallacy, Bayesian reasoning, probability judgment, confirmation, representativeness

Suppose a playing card is randomly drawn from a standard deck and kept hidden from you. Which of the following statements is more probably true?

$$
\begin{aligned}
& \text { The card drawn is black. }\left(h_{1}\right) \\
& \text { The card drawn is black and is an ace. }\left(h_{1} \wedge h_{2}\right)
\end{aligned}
$$

Clearly, the single statement $h_{1}$ would hold for any of the black cards in the deck, whereas only a small fraction of them would make the conjunctive statement $h_{1} \wedge h_{2}$ true. For this plain reason, the former is more likely to prove correct than the latter. This conclusion conforms to a basic and uncontroversial principle known as the conjunction rule of the probability calculus, which says that for any pair of statements $h_{1}$ and $h_{2}$ the probability $(\mathrm{Pr})$

This article was published Online First July 23, 2012.

Katya Tentori, Department of Cognitive Sciences and Education and the Center for Mind/Brain Sciences, University of Trento, Rovereto, Italy; Vincenzo Crupi, Department of Philosophy, University of Torino, and the Munich Center for Mathematical Philosophy, Ludwig Maximilian University of Munich, Munich, Germany; Selena Russo, Department of Cognitive Sciences and Education, University of Trento.

This research was supported by a grant (20083NAH2L) from the Ministero dell'Istruzione, dell'Università e della Ricerca and by the Alexander von Humboldt Foundation.

Correspondence concerning this article should be addressed to Katya Tentori, Department of Cognitive Sciences and Education and the Center for Mind/Brain Sciences, University of Trento, corso Bettini 31, Rovereto 38068, Italy. E-mail: katya.tentori@unitn.it of their conjunction can never be higher than the probability of any of them alone. In formal terms:

$$
\operatorname{Pr}\left(h_{1} \wedge h_{2}\right) \leq \operatorname{Pr}\left(h_{1}\right), \operatorname{Pr}\left(h_{2}\right) .
$$

In case the role of some specific piece of evidence $e$ needs to be explicitly represented as given, a straightforward variant of Equation 1 obtains, as follows:

$$
\operatorname{Pr}\left(h_{1} \wedge h_{2} \mid e\right) \leq \operatorname{Pr}\left(h_{1} \mid e\right), \operatorname{Pr}\left(h_{2} \mid e\right) .
$$

As compelling as it is, the conjunction rule is known to be violated in human intuitive judgment. In certain circumstances, people have a systematic tendency to assess a conjunctive statement as more likely than one of its conjuncts. A number of studies have documented this reasoning error, accordingly labeled the conjunction fallacy. The most widely known illustration is the Linda scenario, taken from the seminal works of Tversky and Kahneman (1982, 1983). When faced with the description of a character, Linda (who is 31 years old, single, outspoken, and very bright, with a major in philosophy; has concerns about discrimination and social justice; and was involved in anti-nuclear demonstrations while a university student), most people ranked the statement "Linda is a bank teller and is active in the feminist movement" as more probable than "Linda is a bank teller," contrary to the conjunction rule.

Notably, the literature also includes different problems eliciting conjunction fallacy effects. Indeed, ever since Tversky and Kahneman's (1983) extensive investigation, the scenarios that are commonly used could be roughly split into a few subsets of cases based on the material employed. The Linda scenario eminently 
instantiates what Tversky and Kahneman themselves called the " $M-A$ paradigm," meaning that some psychologically salient connection exists between a relevant "model" $M$ (i.e., Linda's description) and the added conjunct $A$ (being a feminist activist). At least one further class of scenarios exists, labeled the " $A-B$ paradigm" by Tversky and Kahneman (1983, p. 305), with no specific information conveyed at the outset to describe or evoke a "model," but rather an added conjunct $A$ providing a "plausible cause or motive" for $B$ (i.e., the "basic" hypothesis of interest, which is displayed both in isolation and within the conjunctive statement). As an illustration of the $A-B$ paradigm, Tversky and Kahneman (1983) showed that a majority of participants judged the conjunctive hypothesis that a randomly selected adult male (Mr. F.) "has had one or more heart attacks and is older than 55" as more probable than "has had one or more heart attacks" (the so-called health survey scenario).

The conjunction fallacy is one of the most striking cases in which human intuitive judgment demonstrably departs from sound formal principles of reasoning. Not surprisingly, thus, it has been a key topic in debates on the rationality issue (see Gigerenzer, 1996; Juslin, Nilsson, \& Winman, 2009; Kahneman \& Tversky, 1996; Shier, 2000; Stein, 1996) and has often appeared outside the psychological literature as a paramount illustration of the limitations of human thinking (e.g., Gould, 1992; Rao, 2009; Stich, 1990). Partly because of such widespread interest, claims have been recurrently made that it might not be a real fallacy after all (e.g., Hertwig \& Gigerenzer, 1999; Hintikka, 2004; Levi, 1985). As a matter of fact, most of the subsequent complaints had already been addressed by Tversky and Kahneman (1983). In any event, further refinement of experimental techniques and thorough theoretical scrutiny have clearly shown that the phenomenon is real and in need of explanation (for an extensive review, see Moro, 2009; also see Bonini, Tentori, \& Osherson, 2004; Crupi, Fitelson, \& Tentori, 2008; Sides, Osherson, Bonini, \& Viale, 2002; Sloman, Over, Slovak, \& Stibel, 2003; Stolarz-Fantino, Fantino, Zizzo, \& Wen, 2003; Tentori, Bonini, \& Osherson, 2004; Tentori \& Crupi, 2012b; Wedell \& Moro, 2008). In consideration of the remarkable amount of discussion and research effort that it has prompted in the last 30 years, what is surprising is the lack of a generally accepted explanation of the conjunction fallacy, as pointed out by several observers (e.g., Fisk, 2004; Jarvstad \& Hahn, 2011; Nilsson, Winman, Juslin, \& Hansson, 2009). Accounts have been suggested up to recent times that are very different and still awaiting recognized adjudication on experimental grounds.

\section{Informal Outline}

The present contribution is an inquiry into the determinants of conjunction fallacy effects. For a preliminary and informal illustration, consider the Linda scenario. The added conjunct (being a feminist activist) appears to be fairly probable in light of Linda's description. As we will see shortly, virtually all previous explanations of the conjunction fallacy have identified the relatively high perceived probability of the added conjunct as the main factor on which the phenomenon depends. As a consequence, beyond their specificities, these explanations share the prediction that the tendency to commit the fallacy should increase when the perceived probability of the added conjunct increases. The crucial point of the present contribution is that this widespread implication, as plausible as it may seem at first sight, is ultimately unsound. To grasp that, consider another interesting feature of the Linda scenario. The added conjunct (being a feminist activist) appears not only rather probable in light of Linda's description but also appreciably supported by it. In other terms, getting to know Linda's description clearly increases the credibility of the hypothesis that she is a feminist activist. Thus, the issue arises as to which of these two variables - the perceived probability of the added conjunct versus the perceived support (or inductive confirmation) that the added conjunct receives from relevant information that is available or made salient in the scenario-is critical for the conjunction fallacy.

It is no surprise that this issue has remained experimentally unexplored, for in classical conjunction fallacy scenarios, as in many real-life situations, the two variables of interest are often positively correlated. However, they can radically diverge, as we shall see. Which of them would best predict the occurrence of the conjunction fallacy then? Imagine, for instance, that an item is added in the Linda scenario as follows:

Linda is a bank teller. $\left(h_{1}\right)$

Linda is a bank teller and is active in the feminist movement. $\left(h_{1} \wedge h_{2}\right)$

Linda is a bank teller and owns a pair of black shoes. $\left(h_{1} \wedge h_{2}^{*}\right)$

Presumably, $h_{2}^{*}$ will appear more probable than $h_{2}$ (as almost every woman owns a pair of black shoes, it is very probable that Linda also does) but, unlike $h_{2}$, hardly supported by the specific information conveyed by Linda's description. Would you expect a stronger conjunction fallacy effect in favor of $h_{1} \wedge h_{2}^{*}$ as compared with $h_{1} \wedge h_{2}$ ? If not, then you share the intuition motivating our confirmation-theoretic account of the conjunction fallacy: The perceived probability of the added conjunct is not the key variable to generate the effect. What is crucial for the conjunction fallacy, we submit, is that the added conjunct be perceived as inductively confirmed.

In what follows, we will fill in the theoretical and empirical details of this main argument and work out its implications thoroughly. After a survey of major existing proposals to account for the conjunction fallacy, we will introduce the basics of a probabilistic analysis of inductive confirmation in a more formal fashion and flesh out a confirmation-theoretic approach to the conjunction fallacy. This exposition will clarify how the predictions of our interpretation can be contrasted experimentally with those arising from major alternatives that rely on the perceived probability of the added conjunct as the main determinant of the phenomenon. We will then report four experiments that consistently favor a confirmation-theoretic account of the conjunction fallacy against competing views. Following a summary of the results obtained, we will sketch out a more comprehensive development of our approach, discuss further work from the conjunction fallacy literature, and briefly address related issues concerning human reasoning under uncertainty.

\section{A Survey of Extant Accounts of the Conjunction Fallacy}

\section{Representativeness}

Introducing and commenting on their results with the Linda problem and other similar scenarios, Tversky and Kahneman 
$(1982,1983)$ drew from their general framework for the study of judgment under uncertainty (Tversky \& Kahneman, 1974). They emphasized the role of representativeness, meant as an assessment of the degree of correspondence between a model $(M)$ and some instance or event $(A)$ associated with that model (e.g., connecting Linda's description with the trait mentioned in the added conjunct, i.e., feminist activist).

As recently pointed out by Nilsson et al. (2009, p. 518), textbook treatments of the conjunction fallacy often display the representativeness account-in connection with the Linda casemuch as the standard interpretation of the phenomenon. As popular as it may be, however, this way to present the issue does not seem very well grounded.

To begin with, the representativeness heuristic was not advocated by Tversky and Kahneman as providing a general explanation of conjunction fallacy effects-most notably they meant it as governing results from the $M-A$ paradigm but refrained from explicit reference to the $A-B$ paradigm.

Even in its intended domain of application, the representativeness account has met a remarkable degree of motivated caution and criticism. According to a recurrent complaint in the literature, the main limitation of the notion of representativeness, undermining its explanatory scope, lies in its broadly informal and fuzzy characterization. In particular, it has been claimed (e.g., Gigerenzer, 1996) that the notion of representativeness is unspecified as to both the antecedent conditions which could elicit or suppress it and its underlying cognitive processes. It is not even always clear what should be considered as being representative of what. According to Tversky and Kahneman $(1982,1983)$, representativeness is a directional relation (e.g., normally it is said that a sample is more or less representative of a particular population while it is awkward to describe a population as representative of a sample). Yet, they argue, in some cases, it is possible to reverse the roles of the model and outcome (e.g., "one may evaluate whether a person is representative of the stereotype of librarians or whether the occupation of librarian is representative of that person"; Tversky and Kahneman, 1982, p. 85). When and why this might happen, however, is left open. Hence, the problem remains of identifying scenario by scenario the specific representativeness relation on which the fallacy is expected to depend.

All in all, we concur with several critics pointing out that, despite deserving efforts (e.g., Kahneman \& Frederick, 2002), the standard representativeness account of the conjunction fallacy has not reached a definition that is sharp enough to be put to empirical test in a neat way (see, e.g., Birnbaum, Anderson, \& Hynan, 1990; and, again, Gigerenzer, 1996).

One possible attempt of clarification is that relationships of representativeness can be expressed by means of likelihood values (in the technical sense of the term originally introduced by Fisher, 1922). Such a view implies that people's assessment of posteriors $\operatorname{Pr}\left(h_{1} \mid e\right)$ and $\operatorname{Pr}\left(h_{1} \wedge h_{2} \mid e\right)$ might reflect the evaluation of the corresponding likelihoods $\operatorname{Pr}\left(e \mid h_{1}\right)$ and $\operatorname{Pr}\left(e \mid h_{1} \wedge h_{2}\right)$ (inverse probability account). In Linda's case, for instance, it might well be more likely to find a person matching the description provided $(e)$ among bank tellers who are feminist activists $\left(h_{1} \wedge h_{2}\right)$ than among all bank tellers $\left(h_{1}\right)$. Evidence supporting this approach has been reported by Shafir, Smith, and Osherson (1990) as well as by Massaro (1994), again employing variants of the Linda problem (also see Hertwig \& Chase, 1998, p. 329). However, the inverse probability account does not extend to other scenarios apparently belonging to the same $M-A$ paradigm (see Crupi et al., 2008, p. 192). The Wimbledon scenario from Tversky and Kahneman (1983) provides an effective illustration. Soon after Bjorn Borg's fifth consecutive victory at Wimbledon in 1980 (e) (i.e., when "Borg seemed extremely strong," p. 302), study participants were asked to predict Borg's outcomes in the 1981 Wimbledon tournament. The majority of participants predicted that having reached the finals, Borg would be more likely to lose the first set but win the match $\left(h_{1} \wedge h_{2}\right)$ than he would be to lose the first set $\left(h_{1}\right)$. To account for these data, the inverse probability analysis must imply the utterly implausible judgmental strategy of focusing on the probability of Borg's Wimbledon record, which is in fact an established datum from the past, as conditional on future (hypothetical) events concerning the outcome of the final match.

Overall, the representativeness interpretation of the conjunction fallacy does not seem able to specify the conditions prompting the occurrence of the effect in a general, clear, and convincing fashion. One more twist should be considered, however. In fact, a further way to sharpen the representativeness account is suggested in a subtle remark by Wedell and Moro (2008, p. 128). According to these authors, if Tversky's (1977) contrast model of similarity is employed as a source of clarification, then the representativeness interpretation reflects the application of an averaging model for conjunctive probability judgments. The following section will be devoted precisely to the discussion of averaging models and other related proposals.

\section{Non-Normative Combination Rules}

The consideration of cases such as Linda's may suggest averaging models as a viable account of the conjunction fallacy. To see why, suppose that $\lambda$ denotes the judged likelihood of hypotheses or events, ${ }^{1}$ and notice that $\lambda$, unlike $P r$, is not necessarily constrained by standard probability axioms and principles. An advocate of averaging models would readily point out that a sensible estimate of $\lambda\left(h_{2} \mid e\right)$ in the Linda scenario- that is, the judged probability of her being a feminist activist given the description provided-can be rather high (as much as .85 , according to Birnbaum et al.'s, 1990, illustrative discussion), whereas $\lambda\left(h_{1} \mid e\right)$ - that is, the judged probability of Linda being a bank teller, again given her description — could well be quite low (about .1 for Birnbaum et al., 1990). Under similar assumptions, if $\lambda\left(h_{1} \wedge h_{2} \mid e\right)$ emerges from a simple averaging rule, then one immediately has $\lambda\left(h_{2} \mid e\right)>\lambda\left(h_{1} \wedge h_{2} \mid e\right)>$ $\lambda\left(h_{1} \mid e\right)$, reflecting usually observed patterns of judgment. In a slightly more sophisticated fashion, one can introduce a weighting parameter $\alpha \in(0,1)$, thus postulating a weighted average combination rule for judgments of conjunctive probability (see, e.g., Fantino, Kulik, Stolarz-Fantino, \& Wright, 1997), as follows:

$$
\lambda\left(h_{1} \wedge h_{2} \mid e\right)=\alpha \lambda\left(h_{1} \mid e\right)+(1-\alpha) \lambda\left(h_{2} \mid e\right) .
$$

More recently, Nilsson et al. (2009) advocated a variant of Equation 3 wherein weighting is configural (i.e., depending on the values to be weighted). In particular, they assumed the more likely conjunct to be underweighted: $\alpha<.5$ if $\lambda\left(h_{1} \mid e\right)>\lambda\left(h_{2} \mid e\right)$ and $\alpha>$

\footnotetext{
${ }^{1}$ This notation is freely adapted from Yates and Carlson (1986).
} 
.5 if $\lambda\left(h_{1} \mid e\right)<\lambda\left(h_{2} \mid e\right)$ (see p. 520). ${ }^{2}$ To remove $\alpha$ as a free parameter in their quantitative analyses, Nilsson et al. (2009) provided a theoretical argument to fix $\alpha=.2$ if $\lambda\left(h_{1} \mid e\right)>\lambda\left(h_{2} \mid e\right)$ and $\alpha=.8$ if $\lambda\left(h_{1} \mid e\right)<\lambda\left(h_{2} \mid e\right)$ (p. 523). Abelson, Leddo, and Gross (1987, p. 146) had already considered averaging models with configural weighting.

Notably, Tversky and Kahneman (1983) had already discussed these sorts of accounts, pointing to two substantial shortcomings. First, averaging models in their usual form cannot accommodate double conjunction errors that have been observed (see, e.g., the mile scenario in Tversky \& Kahneman, 1983, p. 306). Suppose that both $h_{1}$ and $h_{2}$ appear in isolation in the experiment. A double conjunction fallacy effect occurs when the conjunction $h_{1} \wedge h_{2}$ is ranked over each of them. Equation 3, however, is mathematically inconsistent with $\lambda\left(h_{1} \wedge h_{2} \mid e\right)>\lambda\left(h_{1} \mid e\right), \lambda\left(h_{2} \mid e\right)$. Second, these models are bound to miss the role of the connection between $h_{1}$ and $h_{2}$, thus facing clear-cut counterexamples. Consider a modified version of the health survey scenario described earlier, and let the isolated conjunct $h_{1}$ state that a randomly selected adult male (Mr. F.) "has had one or more heart attacks" and let the added conjunct $h_{2}$ state that a distinct randomly selected adult male (Mr. G.) "is older than 55." Clearly, the separate likelihoods of $h_{1}$ and $h_{2}$ are left untouched by this modification, so an averaging model would imply no difference in comparison to the standard problem. On the contrary, the rate of conjunction errors dropped dramatically with this material (Tversky \& Kahneman, 1983, p. 306), precisely because the link between the constituent hypotheses had been broken.

Interestingly, there exists one straightforward way to overcome both of these difficulties at once: reformulating the combination rule to include the perceived probability of the added conjunct $h_{2}$ as conditional not only on the specific evidence $e$ available (if any) but also on the single hypothesis of interest $h_{1}$. As a possible motivation for this move, notice that in typical conjunction fallacy scenarios (e.g., both the Linda and the health survey problems) hypothesis $h_{2}$ never occurs alone, but only in conjunction with $h_{1}$. As we will see shortly, such an adjustment provides these models with their most promising outlook, despite being curiously ignored by many of their advocates. In our current notation, $\lambda\left(h_{2} \mid e\right)$ should thus be replaced by $\lambda\left(h_{2} \mid e \wedge h_{1}\right)$. From now on, for any model of the conjunction fallacy relying on a combination rule as applied to the judged probabilities of the conjuncts, we will say that it is refined if it comprises this latter clause. The refined version of Equation 3 would then be as follows:

$$
\lambda\left(h_{1} \wedge h_{2} \mid e\right)=\alpha \lambda\left(h_{1} \mid e\right)+(1-\alpha) \lambda\left(h_{2} \mid e \wedge h_{1}\right)
$$

Formally, Equation 4 does allow for double conjunction fallacies, that is, for both inequalities $\lambda\left(h_{1} \wedge h_{2} \mid e\right)>\lambda\left(h_{1} \mid e\right)$ and $\lambda\left(h_{1} \wedge h_{2} \mid e\right)>\lambda\left(h_{2} \mid e\right) .^{3}$ Under only a couple of undemanding caveats, moreover, it also captures the health survey case discussed previously. To see how, first recall that no specific information is provided at the outset in this kind of experimental problem. We will thus treat $e$ as empty for our current purposes. As a consequence, we have Equation 4 reduced to the following:

$$
\lambda\left(h_{1} \wedge h_{2}\right)=\alpha \lambda\left(h_{1}\right)+(1-\alpha) \lambda\left(h_{2} \mid h_{1}\right) .
$$

Now $\lambda\left(h_{2} \mid h_{1}\right)$ is presumably higher than $\lambda\left(h_{1}\right)$ in both versions of Tversky and Kahneman's (1983) health survey scenario (recall that $h_{1}$ concerns having had one or more heart attacks and $h_{2}$ being older than 55) and quite clearly higher in the standard version (involving one and the same individual, Mr. F.) than in the modified version (involving two different people, Mr. F. and Mr. G.). So, by Equation 5, a larger effect is indeed expected in the former compared with the latter, which is just what the data show.

Another way to model conjunction fallacy effects is provided by multiplicative combination rules. In our current notation, their general (refined) form is the following:

$$
\lambda\left(h_{1} \wedge h_{2} \mid e\right)=\lambda\left(h_{1} \mid e\right)^{\alpha} \times \lambda\left(h_{2} \mid e \wedge h_{1}\right)^{\beta} .
$$

Equation 6 would reduce to a theorem of standard probability for $\alpha=\beta=1$, whereas for $\alpha=1-\beta$, it yields a (refined) geometric mean model allowing for non-normative judgment (see, e.g., Abelson et al., 1987). Birnbaum et al. (1990) employed their conjunction fallacy data set to fix best fitting values for $\alpha$ and $\beta$ (obtaining .54 and .68 , respectively). Furthermore, a refined version of Einhorn's (1985) multiplicative configural model - in which "more probable components should receive larger weights" (p. 5)—also arises from Equation 5 by setting $\alpha=1-\lambda\left(h_{1} \mid e\right)$ and $\beta=1-\lambda\left(h_{2} \mid e \wedge h_{1}\right)$.

Finally, signed summation should be mentioned as another important model of the conjunction fallacy based on a nonnormative combination rule (Yates \& Carlson, 1986). In our notation, a refined version of the signed summation model can be formalized as follows:

$$
\lambda\left(h_{1} \wedge h_{2} \mid e\right)=\lambda\left(h_{1} \mid e\right)+\lambda\left(h_{2} \mid e \wedge h_{1}\right)-1 / 2 .
$$

(with the caveat that the value of $\lambda\left(h_{1} \wedge h_{2} \mid e\right)$ be truncated upwards and downwards at 1 and 0 , respectively).

For our present purposes, the crucial point of the foregoing survey is that each of the non-normative combination rules that have been proposed is an increasing function of the judged probability of the added conjunct, that is, in its more tenable (refined) version, an increasing function of $\lambda\left(h_{2} \mid e \wedge h_{1}\right)$. Accordingly, these models - despite their interesting differences-all share one common empirical implication, which is that the extent of the conjunction fallacy effect should increase as $\lambda\left(h_{2} \mid e \wedge h_{1}\right)$ increasesprovided, of course, that $\lambda\left(h_{1} \mid e\right)$ is kept constant. This statement will be central in our experiments described in the sections that follow. Before coming to that, however, we will need to consider a few more competing accounts of the conjunction fallacy.

\section{Models of Rationality Rescue}

In stark contrast with the ones mentioned previously, the proposals considered in this section attribute systematically normative patterns of reasoning to experimental participants. Notably, this does not mean that the conjunction fallacy results are criticized as experimental artifacts depending on subtle "pragmatic" factors. As

\footnotetext{
${ }^{2}$ A different way to constrain $\alpha$ and fulfill Nilsson et al.'s (2009) assumptions amounts to positing the following:

$$
\alpha=\frac{1-\lambda\left(h_{1} \mid e\right)}{\left[1-\lambda\left(h_{1} \mid e\right)\right]+\left[1-\lambda\left(h_{2} \mid e\right)\right]} .
$$

${ }^{3}$ For a simple proof, assume equal weights $(\alpha=.5)$ along with the following assignments: $\lambda\left(h_{1} \mid e\right)=\lambda\left(h_{2} \mid e\right)=.2 ; \lambda\left(h_{1} \mid e \wedge h_{2}\right)=\lambda\left(h_{2} \mid e \wedge h_{1}\right)=$ .4. Then the model in Equation 4 yields $\lambda\left(h_{1} \wedge h_{2} \mid e\right)=.3>\lambda\left(h_{1} \mid e\right), \lambda\left(h_{2} \mid e\right)$.
} 
we will see shortly, the claim that probabilistic incoherence is unnecessary to account for the data is made on the basis of a theoretical engagement from a different source.

One of the most recent additions to the list of proposed explanations of the conjunction fallacy is due to Costello (2009), who displayed a significant effort of elaboration to articulate the model in formal terms and to bridge it to existing results and some novel data. For our present purposes, however, a brief outline will be sufficient. First of all, the model overtly assumes that people's subjective degrees of belief do satisfy normative probabilistic principles governing conjunctive hypotheses, especially including the following:

$$
\operatorname{Pr}\left(h_{1} \wedge h_{2} \mid e\right)=\operatorname{Pr}\left(h_{1} \mid e\right) \times \operatorname{Pr}\left(h_{2} \mid e \wedge h_{1}\right) .
$$

When expressed in concrete judgment tasks, however, such probabilistic degrees of belief allegedly become affected by random error variation. Precisely because of this random variation, it is submitted, the judged probability of a single conjunct $h_{1}$ and that of the conjunction $h_{1} \wedge h_{2}$ may appear in a reversed, non-normative rank order on a given occasion, thus allowing for the occurrence of conjunction fallacy effects. Such a pattern will be more likely to show up the closer the postulated "real" subjective value of $\operatorname{Pr}\left(h_{1} \wedge h_{2} \mid e\right)$ is to that of $\operatorname{Pr}\left(h_{1} \mid e\right)$, that is, the more the value of $\operatorname{Pr}\left(h_{2} \mid e \wedge h_{1}\right)$ approaches unity (see Equation 8). Thus, once again, a higher perceived probability of the added conjunct is expected to foster the conjunction fallacy effect.

Another highly sophisticated proposal for modeling conjunction fallacy problems has been described by Bovens and Hartmann (2003). Let us begin with an informal rendition of the argument, referred to as the Linda case. Suppose that Linda's description $(e)$ is known. "Linda is a bank teller" $\left(h_{1}\right)$ and "Linda is a bank teller and a feminist activist" $\left(h_{1} \wedge h_{2}\right)$, on the other hand, are assumed to be reports of two distinct sources of information that may or may not be reliable. According to Bovens and Hartmann (2003), evidence $e$ allows for very different assessments of reliability depending on the source and its report. In particular, if the source only reports $h_{1}$ (label this fact $r_{1}$ ), then $e$ suggests that it is probably unreliable; however, in case the source reports $h_{1} \wedge h_{2}$ (label this fact $r_{2}$ ), its probability of being reliable would be higher. Notably, it is perfectly possible for the probability of statement $h_{1}$ as reported by a source that is probably unreliable to be lower than the probability of statement $h_{1} \wedge h_{2}$ as reported by a source that is probably reliable. Bovens and Hartmann (2003) submit that this is what usual participants' responses express, and they provide (pp. 85-88) a Bayesian network representation of the relevant probabilistic dependencies yielding the following:

$$
\operatorname{Pr}\left(h_{1} \wedge h_{2} \mid e \wedge r_{2}\right)=\frac{\operatorname{Pr}\left(h_{1} \mid e\right) \operatorname{Pr}\left(h_{2} \mid e\right)\left[\rho+a^{2}(1-\rho)\right]}{\operatorname{Pr}\left(h_{1} \mid e\right) \operatorname{Pr}\left(h_{2} \mid e\right) \rho+a^{2}(1-\rho)},
$$

where $\rho$ is the prior probability that the source is reliable (meaning completely trustworthy) and $a$ is the overall chance that, if unreliable, it yields any of the reports at issue, $h_{1}$ and $h_{2}$, respectively (i.e., that Linda is indeed a bank teller and that she is indeed a feminist activist). From Bovens and Hartmann's (2003) analysis (which also involved positing $\rho=a=.5$ ), it follows that $\operatorname{Pr}\left(h_{1} \wedge h_{2} \mid e \wedge r_{2}\right)$ is higher than $\operatorname{Pr}\left(h_{1} \mid e \wedge r_{1}\right)$ provided that $\operatorname{Pr}\left(h_{2} \mid e\right)$ is significantly higher than $\operatorname{Pr}\left(h_{1} \mid e\right)$, as it seems to be in the Linda case. Substantial concerns have been raised about how closely this analysis matches the information and task actually presented in the experimental settings of interest (see Crupi et al., 2008, p. 190; Olsson, 2005, p. 292). ${ }^{4}$ Also, a first empirical test provided rather unfavorable results (see Jarvstad \& Hahn, 2011). Be that as it may, for our present purposes it is relevant to notice that in this model the probability of the conjunction to be assessed is demonstrably an increasing function of $\operatorname{Pr}\left(h_{2} \mid e\right)$. Bovens and Hartmann (2003) also treated $h_{1}$ and $h_{2}$ as independent (with $e$ being given), thus assuming $\operatorname{Pr}\left(h_{2} \mid e\right)=\operatorname{Pr}\left(h_{2} \mid e \wedge h_{1}\right)$. As a consequence, just like the ones described, their analysis also implied that a stronger conjunction fallacy effect should be expected if the perceived probability of the added conjunct increases (as far as the perceived probability of the isolated conjunct is kept constant).

The accounts listed in the foregoing pages involve a variety of quite different assumptions and implications concerning human judgment. Yet all of them-along with others that have not been included for the sake of brevity (see, e.g., Busemeyer, Franco, Pothos, \& Trueblood, 2011, and Franco, 2009)_converge on the widely shared view that the perceived probability of the added conjunct is a crucial factor governing the occurrence of conjunction fallacy effects. This means that in otherwise controlled conditions, the more probable the added conjunct, the stronger the conjunction fallacy effect to be expected. As anticipated, we will now turn to an alternative approach that departs from this conclusion and identifies a different kind of variable as a major determinant of conjunction errors in probability judgment.

\section{A Different Perspective: Inductive Confirmation and the Conjunction Fallacy}

\section{What Inductive Confirmation Is (and How It Differs From Posterior Probability)}

Consider a modified version of our very initial example. Recall the basic scenario, namely, a playing card has been drawn at random from a standard deck and kept out of your sight. We will now simply focus on two complementary hypotheses:

The card drawn is a king $(h)$

The card drawn is not a king (not- $h$ )

Suppose that, while the card is still kept hidden, one additional piece of information is provided:

The card drawn is a picture $(e)$

By learning $e$, something happens that is of crucial interest for our current purposes, as the following relations show:

$$
\begin{gathered}
\operatorname{Pr}(h \mid e)=1 / 3>1 / 13=\operatorname{Pr}(h) \\
\operatorname{Pr}(\text { not }-h \mid e)=2 / 3<12 / 13=\operatorname{Pr}(\text { not }-h) .
\end{gathered}
$$

\footnotetext{
${ }^{4}$ One significant problem is that in within-subjects experiments, each participant would clearly become aware of both reports $r_{1}$ and $r_{2}$ (along with $e$ ). Thus, in these cases, judgments concerning $h_{1}$ and $h_{1} \wedge h_{2}$ should be modeled as conditionalized on the same set of statements (viz. $e, r_{1}$ and $r_{2}$ ). But then Bovens and Hartmann's (2003) analysis fails to apply, while the conjunction rule comes back as a straightforward formal constraint.
} 
Due to evidence $e$, the probability of hypothesis $h$ has increased from about $.08(1 / 13)$ up to about $.33(1 / 3)$, while the probability of not- $h$ has decreased from about .92 (12/13) down to about .67 (2/3). Thus, evidence $e$ has strengthened the credibility of hypothesis $h$ and weakened that of not- $h$. Notably, this is so despite that not- $h$ is still the more likely overall, as $\operatorname{Pr}($ not- $h \mid e)=2 / 3>1 / 3=$ $\operatorname{Pr}(h \mid e)$; hence, the net effect of evidence $e$ as supporting $h$ and undermining not- $h$ is not conveyed by final (posterior) probability values alone.

This simple example illustrates a major conceptual distinction that has been long known and discussed in the logical analysis of inductive reasoning: the difference between posterior probability and inductive confirmation - or, in Carnap's (1962, pp. xv-xx) telling terminology, between firmness and increase in firmness (for a very useful survey, see Fitelson, 2005). Inductive confirmation is a relative notion in the following crucial sense: the credibility of a hypothesis can be changed by a given piece of evidence in either a positive (confirmation in a narrow sense) or negative way (disconfirmation). Confirmation (in the narrow sense) thus reflects an increase from prior to posterior probability, whereas disconfirmation reflects a decrease. As confirmation concerns the relationship between prior and posterior, there is simply no single probability value that can capture the notion. As John Irving Good once effectively pointed out, "If you had $\operatorname{Pr}(h \mid e)$ close to unity, but less than $\operatorname{Pr}(h)$, you ought not to say that $h$ was confirmed by $e^{\text {" }}$ (Good, 1968, p. 134). As neat as it is, the distinction between posterior probability and inductive confirmation has proved a recurrent need for theoretical clarity in philosophy (Peijnenburg, 2012; Popper, 1954), artificial intelligence (Horvitz \& Heckerman, 1986), and the psychology of reasoning alike (Crupi et al., 2008; Sides et al., 2002).

A natural way to formalize inductive confirmation amounts to positing a function $c(h, e)$ mapping relevant probability values onto a number that is positive, null, or negative, depending on the posterior of $h$ being higher, equal, or lower than its prior, i.e.:

$$
c(h, e)\left\{\begin{array}{lll}
>0 & \text { iff } & \operatorname{Pr}(h \mid e)>\operatorname{Pr}(h) \\
=0 & \text { iff } & \operatorname{Pr}(h \mid e)=\operatorname{Pr}(h) \\
<0 & \text { iff } & \operatorname{Pr}(h \mid e)<\operatorname{Pr}(h)
\end{array}\right.
$$

Various alternative quantitative models of confirmation have been proposed and defended that satisfy the basic qualitative constraint in Equation 11. Here, however, we will not need to go into any detail concerning competing formal measures of confirmation. ${ }^{5}$ More important, previous research has shown that intuitive assessments of confirmation can be elicited directly and that people can distinguish confirmation from posterior probability (see Mastropasqua, Crupi, \& Tentori, 2010; Tentori, Crupi, Bonini, \& Osherson, 2007).

\section{A Confirmation-Theoretic Framework for the Conjunction Fallacy}

A confirmation-theoretic framework for the conjunction fallacy has been presented by Crupi et al. (2008) and Tentori and Crupi (2012a), who also discussed a number of earlier contributions that are more or less strictly related (see Lagnado \& Shanks, 2002; Levi, 2004; Sides et al., 2002; Tenenbaum \& Griffiths, 2001). According to this account, the occurrence of a conjunction fallacy effect concerning $h_{1} \wedge h_{2}$ crucially depends on inductive confirmation as referred to the added conjunct $h_{2}$. As we will see now, the classical experimental paradigms $(M-A$ and $A-B)$ can be seen as instantiating this common principle in distinct ways.

A critical feature of the $M-A$ paradigm is that a specific piece of evidence $e$ available to participants (e.g., Linda's description) provides inductive confirmation to the added conjunct $h_{2}$ (being a feminist activist) even conditional on the other conjunct $h_{1}$ (being a bank teller), that is, even if $h_{1}$ is concurrently assumed to hold. In terms of Bayesian confirmation theory, the variable at issue is denoted as $c\left(h_{2}, e \mid h_{1}\right)$ and reflects the departure of $\operatorname{Pr}\left(h_{2} \mid e \wedge h_{1}\right)$ from $\operatorname{Pr}\left(h_{2} \mid h_{1}\right){ }^{6}$ We thus submit that on otherwise controlled conditions, the occurrence of the conjunction fallacy in the $M-A$ paradigm essentially depends on a relatively high perceived value of $c\left(h_{2}, e \mid h_{1}\right)$. Alternative accounts of the conjunction fallacy presented earlier, by contrast, rely on a relatively high perceived value of $\operatorname{Pr}\left(h_{2} \mid e \wedge h_{1}\right)$ as a predictor of the effect.

The $A-B$ paradigm can also be addressed in a similar vein, that is, in terms of the added conjunct $h_{2}$ being perceived as inductively confirmed. Here, the confirmatory impact on the added conjunct $h_{2}$ (e.g., being older than 55 in the health survey scenario) arises from the connection with the other conjunct $h_{1}$ (having had one or more heart attacks). We thus submit that on otherwise controlled conditions, the occurrence of the conjunction fallacy in the $A-B$ paradigm essentially depends on a relatively high perceived value of $c\left(h_{2}, h_{1}\right)$, that is, the departure of $\operatorname{Pr}\left(h_{2} \mid h_{1}\right)$ from $\operatorname{Pr}\left(h_{2}\right)$. Alternative analyses presented earlier, by contrast, rely on a relatively high perceived value of $\operatorname{Pr}\left(h_{2} \mid h_{1}\right)$ as a predictor of the effect.

Although already advocated through theoretical and empirical arguments (Crupi et al., 2008; Tentori \& Crupi, 2012a), our view has never been put to direct test in contrast to major alternatives, as those listed in the previous sections. In this respect, moreover, extant experimental results are largely inconsequential. In fact, as anticipated, the most widely debated $M-A$ scenarios, such as Linda's, do not discriminate, as the added conjunct $h_{2}$ (e.g., being a feminist activist) appears to be both fairly probable and appreciably confirmed by the specific evidence $e$ (Linda's description),

\footnotetext{
${ }^{5}$ As a matter of fact, experimentation and theoretical analysis have so far singled out the following two models as particularly appealing on both descriptive and normative grounds (for brevity of notation, $O$ denotes odds, so that $O(h)=\operatorname{Pr}(h) / \operatorname{Pr}($ not $-h)$ and $O(h \mid e)=\operatorname{Pr}(h \mid e) / \operatorname{Pr}($ not $-h \mid e))$ :

$$
\begin{gathered}
L(h, e)=\frac{O(h \mid e)-O(h)}{O(h \mid e)+O(h)} \\
Z(h, e)=\left\{\begin{array}{l}
\frac{\operatorname{Pr}(h \mid e)-\operatorname{Pr}(h)}{1-\operatorname{Pr}(h)} \quad \text { if } \quad \operatorname{Pr}(h \mid e) \geq \operatorname{Pr}(h) \\
\frac{\operatorname{Pr}(h \mid e)-\operatorname{Pr}(h)}{\operatorname{Pr}(h)} \quad \text { if } \quad \operatorname{Pr}(h \mid e)<\operatorname{Pr}(h)
\end{array}\right.
\end{gathered}
$$

where $L$ is an increasing function of the likelihood ratio and $\mathrm{Z}$ is a relative distance measure of confirmation. For relevant results and arguments, see Crupi, Festa, and Buttasi (2010); Crupi and Tentori (2010); Crupi, Tentori and Gonzalez (2007); Earman (1992); Festa (1999); Fitelson (2006); Mastropasqua et al. (2010); Tentori et al. (2007).

${ }^{6}$ Note that the confirmatory impact of $e$ on $h_{2}$ conditional on $h_{1}$ is formally and conceptually distinct from how $h_{2}$ is affected by $e$ and $h_{1}$ taken as a joint item of evidence. As pointed out in the text, the former quantity reflects the relationship between $\operatorname{Pr}\left(h_{2} \mid e \wedge h_{1}\right)$ and $\operatorname{Pr}\left(h_{2} \mid h_{1}\right)$; for the latter, on the contrary, the relevant probabilistic values are $\operatorname{Pr}\left(h_{2} \mid e \wedge h_{1}\right)$ and $\operatorname{Pr}\left(h_{2}\right)$.
} 
even if the other conjunct $h_{1}$ (being a bank teller) is concurrently assumed to hold. So in this case, the two variables to be contrasted, $\operatorname{Pr}\left(h_{2} \mid e \wedge h_{1}\right)$ and $c\left(h_{2}, e \mid h_{1}\right)$, point in the same direction, as it were. Similarly, in typical $A-B$ scenarios, the added conjunct $h_{2}$ (e.g., being older than 55 in the health survey scenario) may well appear rather likely as well as confirmed relative to $h_{1}$ (having had one or more heart attacks). However, probability and confirmation may radically depart in other cases, as pointed out in the foregoing. In the remainder of the article, we will show how dissociation of these two distinct variables can be conveniently achieved in scenarios akin to those usually employed in conjunction fallacy experiments, thus providing a direct empirical test of predictions arising from the confirmation-theoretic account as contrasted to major existing alternatives.

\section{The Experiments: An Overview of Their Structure}

We conducted four experiments sharing the same basic procedure. In all of them, participants were presented with three statements of the form $h_{1}, h_{1} \wedge h_{2}$, and $h_{1} \wedge h_{3}$. Hypotheses $h_{2}$ and $h_{3}$ appearing in the conjunctions were selected in such a way that one $\left(h_{2}\right)$ ranked higher than the other $\left(h_{3}\right)$ in assessments of confirmation, but equal or lower in judged probability.

Control procedures for these rankings were of crucial importance in the experimental set-up. For an illustration of the confirmation task adopted, consider a hypothetical individual O., and suppose he or she is an expert mountaineer $\left(h_{1}\right)$. You are presented with two hypotheses, namely, "O. gives music lessons" $\left(h_{2}\right)$ and "O. owns an umbrella" $\left(h_{3}\right)$. Then you are provided with the piece of information that "O. has a degree in violin performance" $(e)$ and are asked to evaluate how it impacts on the two target hypotheses $h_{2}$ and $h_{3}$. You would presumably concur that, even on the background assumption that $\mathrm{O}$. is an expert mountaineer, $\mathrm{O}$. having a degree in violin performance confirms to some extent the hypothesis that $\mathrm{O}$. gives music lessons, while being quite irrelevant to O.'s owning an umbrella. If so, your assessment implies that $c\left(h_{2}, e \mid h_{1}\right)>c\left(h_{3}, e \mid h_{1}\right)$. The picture would presumably change, however, were you asked about the corresponding probabilities. Then you could reason that an expert mountaineer $\left(h_{1}\right)$ with a degree in violin performance $(e)$, like almost everybody, is definitely likely to own an umbrella $\left(h_{3}\right)$-in fact, at least likely as he or she is to give music lessons $\left(h_{2}\right)$. If so, your assessment implies that $\operatorname{Pr}\left(h_{2} \mid e \wedge h_{1}\right) \leq \operatorname{Pr}\left(h_{3} \mid e \wedge h_{1}\right)$. To sum up, you would have ranked "O. gives music lessons" $\left(h_{2}\right)$ as more inductively confirmed but equally or less probable than "O. owns an umbrella" $\left(h_{3}\right)$ in light of the relevant evidence. As anticipated, we used pairs of hypotheses of this kind to build the conjunctive statements included in our conjunction fallacy problems. The following is an example from Experiment 2:

O. has a degree in violin performance. $[e]$

Which of the following hypotheses do you think is the most probable?

$\square$ O. is an expert mountaineer $\left[h_{1}\right.$, correct option]

$\square$ O. is an expert mountaineer and gives music lessons $\left[h_{1} \wedge h_{2}\right.$, conjunction fallacy]

$\square$ O. is an expert mountaineer and owns an umbrella $\left[h_{1} \wedge h_{3}\right.$, conjunction fallacy]

This paradigm allowed us to perform a direct test of different accounts of the conjunction fallacy described in the previous sections. In particular, if perceived confirmation of the added conjunct is the key determinant of the conjunction fallacy, fallacious responses should target $h_{1} \wedge h_{2}$ more than $h_{1} \wedge h_{3}$. On the other hand, if the perceived probability of the added conjunct is the key determinant of the conjunction fallacy, fallacious responses should target $h_{1} \wedge h_{2}$ as much as $h_{1} \wedge h_{3}$ (in the case of $h_{2}$ and $h_{3}$ ranking equal in probability judgment) or should target $h_{1} \wedge h_{2}$ less than $h_{1} \wedge h_{3}$ (in the case of $h_{2}$ ranking lower than $h_{3}$ in probability judgment).

\section{Experiment 1}

We started our empirical inquiry from the $M-A$ paradigm. In Experiment 1, the hypotheses involved in the conjunction fallacy task had the following formal structure: $h_{1}, h_{1} \wedge h_{2}$, and $h_{1} \wedge$ not $-h_{2}$. Therefore, one of the two added conjuncts (not- $h_{2}$ ) was simply the negation of the other $\left(h_{2}\right)$. This allowed us to elicit both confirmation and probability judgments in a comparative fashion (for a detailed description of the experimental questions used, see the "Design, procedure, and materials" section that follows and Appendix A). ${ }^{7}$

\section{Method}

Participants. Participants were 177 undergraduates (104 females; mean age: 22.96 years) from the Trento University and Milan-Bicocca University.

Design, procedure, and materials. We employed a betweensubjects design. Participants were interviewed individually and randomly divided into three groups, one for each among three (probability, confirmation, and conjunction fallacy) tasks. The stimuli included two experimental scenarios (the Russian woman and the American man scenarios, both provided in Appendix A), and four fillers, whose structure was seemingly similar to that of the experimental scenarios but with no connection to the conjunction rule (for example, the logical form of the three hypotheses appearing in some of the fillers was: $h_{1}, h_{2} \wedge h_{3}$, and $h_{2} \wedge$ not- $h_{3}$ ). In what follows, we will only report the details that are pertinent to the experimental scenarios.

The probability task was meant to check, for each of the two scenarios, if the majority of participants judged $\operatorname{Pr}\left(h_{2} \mid e \wedge h_{1}\right)$ as higher or lower than $\operatorname{Pr}\left(\right.$ not $\left.-h_{2} \mid e \wedge h_{1}\right)$. Accordingly, we provided $e$ along with $h_{1}$ as given information, and then we asked whether either hypothesis $h_{2}$ or not- $h_{2}$ was more probable in light of such information.

The confirmation task was meant to check, for each of the two scenarios, if the majority of participants judged $c\left(h_{2}, e \mid h_{1}\right)$ as higher or lower than $c\left(\right.$ not- $\left.h_{2}, e \mid h_{1}\right)$. Accordingly, we first provided $h_{1}$ as a piece of background information and instructed the participants to consider $h_{2}$ as a hypothesis (i.e., as a statement that could be true or false). Then we provided statement $e$ as a piece of newly given evidence and asked whether hypothesis $h_{2}$ was either strengthened or weakened by such evidence compared with its prior background credibility. ${ }^{8}$ (For a validation of this kind of procedure as effectively eliciting confirmation rather than posterior probability judgments, see Mastropasqua et al., 2010, and Tentori et al., 2007.)

Finally, the conjunction fallacy task was meant to detect, for each of the two scenarios, the occurrence of conjunction fallacy

\footnotetext{
${ }^{7}$ All materials are translated from Italian.

${ }^{8}$ Notice that $c\left(h_{2}, e \mid h_{1}\right)>0$ implies $c\left(\right.$ not- $\left.h_{2}, e \mid h_{1}\right)<0$, and therefore $c\left(h_{2}, e \mid h_{1}\right)>c\left(\right.$ not $\left.-h_{2}, e \mid h_{1}\right) ;$ symmetrically, $c\left(h_{2}, e \mid h_{1}\right)<0$ implies $c\left(\right.$ not- $\left.h_{2}, e \mid h_{1}\right)>0$, and therefore $c\left(h_{2}, e \mid h_{1}\right)<c\left(\right.$ not- $\left.h_{2}, e \mid h_{1}\right)$.
} 
responses and their distribution between $h_{1} \wedge h_{2}$ versus $h_{1} \wedge$ not $-h_{2}$. Accordingly, we provided $e$ as a given piece of evidence and then asked which among $h_{1}, h_{1} \wedge h_{2}$, or $h_{1} \wedge$ not- $h_{2}$ was most probable in light of such evidence (the position of the three options in the stimuli was balanced across participants).

\section{Results and Discussion}

The results of the probability task are displayed in Table 1. No significant difference emerged at a one-sample binomial test between the judged probability of $h_{2}$ and not- $h_{2}$ in both the Russian woman and the American man scenarios (37\% vs. $63 \%$, ns, twosided, and $47 \%$ vs. $53 \%$, $n s$, two-sided, respectively).

The results of the confirmation task are displayed in Table 2. A one-sample binomial test revealed that $h_{2}$ rather than not- $h_{2}$ was judged as confirmed by most participants in both the Russian woman and the American man scenarios (80\% vs. 20\%, $p<.05$, two-sided, and $88 \%$ vs. $12 \%, p<.01$, two-sided, respectively).

Therefore, for both scenarios, $h_{2}$ ranked higher than not $h_{2}$ in assessments of confirmation but not in judged probability, allowing us to dissociate the effects of confirmation versus probability of the added conjunct on conjunction fallacy rates. According to our analysis, the conjunction fallacy rate attached to $h_{1} \wedge h_{2}$ should be higher than that for $h_{1} \wedge$ not- $h_{2}$ (because $h_{2}$ rather than not- $h_{2}$ is predominantly seen as confirmed in the experimental scenarios). According to the other accounts previously considered, however, a different pattern should obtain; that is, there should be no difference in the conjunction fallacy rates attached to $h_{1} \wedge h_{2}$ and $h_{1} \wedge$ not- $h_{2}$ (because none between $h_{2}$ and not- $h_{2}$ is predominantly seen as more probable).

The results of the conjunction fallacy task are displayed in Table 3. A minority of participants chose the correct option $h_{1}(22 \%$ and $20 \%$ in the Russian woman and American man scenarios, respectively). Among the participants providing fallacious responses, a large majority chose the conjunction for which the added conjunct ranked higher in assessments of confirmation but not in judgments of probability. More precisely, the preferences for $h_{1} \wedge h_{2}$ versus $h_{1} \wedge$ not $-h_{2}$ were $70 \%$ versus $30 \%$ and $77 \%$ versus $23 \%$ in the Russian woman and American man scenarios, respectively (all distributions are significantly different from the $50 \%$ vs $50 \%$ chance level by one-sample binomial test, $p<.02$, two-sided).

The results presented support our reading of the conjunction fallacy as depending on the perceived confirmation of the added conjunct. A convergent argument arises from a comparison be-

Table 1

Distribution of the Participants According to Their Responses in the Probability Task (Experiment 1)

\begin{tabular}{|c|c|c|c|c|}
\hline \multirow[b]{2}{*}{ Response } & \multicolumn{2}{|c|}{$\begin{array}{l}\text { Russian woman } \\
\text { scenario } \\
(N=59)\end{array}$} & \multicolumn{2}{|c|}{$\begin{array}{c}\text { American man } \\
\text { scenario } \\
(N=59)\end{array}$} \\
\hline & $N$ & $\%$ & $N$ & $\%$ \\
\hline $\begin{array}{l}\operatorname{Pr}\left(h_{2} \mid e \wedge h_{1}\right)>\operatorname{Pr}\left(\text { not }-h_{2} \mid e \wedge h_{1}\right) \\
\operatorname{Pr}\left(h_{2} \mid e \wedge h_{1}\right)<\operatorname{Pr}\left(\text { not }-h_{2} \mid e \wedge h_{1}\right)\end{array}$ & $\begin{array}{l}22 \\
37\end{array}$ & $\begin{array}{l}37 \\
63\end{array}$ & $\begin{array}{l}28 \\
31\end{array}$ & $\begin{array}{l}47 \\
53\end{array}$ \\
\hline
\end{tabular}

Note. $\operatorname{Pr}=$ probability; $h_{1}=$ isolated conjunct; $h_{2}=$ added conjunct (the most confirmed); not- $h_{2}=$ added conjunct (the most probable).
Table 2

Distribution of the Participants According to Their Responses in the Confirmation Task (Experiment 1)

\begin{tabular}{cccccc}
\hline & $\begin{array}{c}\text { Russian woman } \\
\text { scenario } \\
(N=59)\end{array}$ & & \multicolumn{2}{c}{$\begin{array}{c}\text { American man } \\
\text { scenario } \\
(N=59)\end{array}$} \\
\cline { 2 - 3 } Response & $N$ & $\%$ & & $N$ & $\%$ \\
\hline$c\left(h_{2}, e \mid h_{1}\right)>c\left(\right.$ not $\left.-h_{2}, e \mid h_{1}\right)$ & 47 & $80 \%$ & & 52 & $88 \%$ \\
$c\left(h_{2}, e \mid h_{1}\right)<c\left(\right.$ not $\left.-h_{2}, e \mid h_{1}\right)$ & 12 & $20 \%$ & & 7 & $12 \%$ \\
\hline
\end{tabular}

Note. $\quad c=$ confirmation; $h_{1}=$ isolated conjunct; $h_{2}=$ added conjunct (the most confirmed); not- $h_{2}=$ added conjunct (the most probable).

tween the responses in the two scenarios of Experiment 1. As Tables 2 and 3 show, moving from the Russian woman to the American man scenario, one finds a $8 \%$ increase/decrease concerning confirmation of $h_{2} /$ not- $h_{2}$, and a corresponding $7 \%$ increase/decrease in the fallacy rate for $h_{1} \wedge h_{2} / h_{1} \wedge$ not- $h_{2}$, that is, an almost perfect match between the variations in the conjunction fallacy rates and confirmation judgments.

\section{Experiment 2}

Experiment 1 lent initial support to our confirmation-theoretic account of the conjunction fallacy compared with alternative interpretations by which the perceived probability of the added conjunct counts as the main critical variable. In Experiment 2, we examined if the results extend to other scenarios with different content and no hypothesis in the stimuli expressed as a negation. The latter caution was meant to dispel a potential concern regarding the previous experiment - that in both scenarios the added conjunct being predominantly judged as confirmed $\left(h_{2}\right)$ was also affirmative in mode, unlike the other (not- $h_{2}$ ). (For a recent debate on the affirmative/negative statement asymmetry and further references, see Giora, 2006, and Kaup, Lüdtke, \& Zwaan, 2006.) Experiment 2 is similar to Experiment 1, but in Experiment 2, this possible source of confound is ruled out. In each scenario, the added conjuncts $h_{2}$ and $h_{3}$ always appeared in affirmative mode. This modification also prompted a different elicitation procedure (absolute instead of comparative) for both confirmation and probability judgments (for a detailed description of the experimental

Table 3

Distribution of the Participants According to Their Responses in the Conjunction Fallacy Task (Experiment 1)

\begin{tabular}{|c|c|c|c|c|c|c|}
\hline \multirow[b]{2}{*}{ Response } & \multicolumn{3}{|c|}{$\begin{array}{c}\text { Russian woman } \\
\text { scenario } \\
(N=59)\end{array}$} & \multicolumn{3}{|c|}{$\begin{array}{c}\text { American man } \\
\text { scenario } \\
(N=59)\end{array}$} \\
\hline & $N$ & $\%$ & $\%$ & $N$ & $\%$ & $\%$ \\
\hline$h_{1}$ & 13 & 22 & & 12 & 20 & \\
\hline$h_{1} \wedge h_{2}$ & 32 & 54 & 70 & 36 & 61 & 77 \\
\hline$h_{1} \wedge$ not $-h_{2}$ & 14 & 24 & 30 & 11 & 19 & 23 \\
\hline
\end{tabular}

Note. $\quad h_{1}=$ isolated conjunct; $h_{2}=$ added conjunct (the most confirmed); not $-h_{2}=$ added conjunct (the most probable). 
Table 4

Average Estimates in the Probability Task (Experiment 2) (for Each Average $N=30$ )

\begin{tabular}{lcccc}
\hline Response & $\begin{array}{c}\text { Violinist } \\
\text { scenario }\end{array}$ & $\begin{array}{c}\text { Swiss man } \\
\text { scenario }\end{array}$ & $\begin{array}{c}\text { Student } \\
\text { scenario }\end{array}$ & $\begin{array}{c}\text { Swedish girl } \\
\text { scenario }\end{array}$ \\
\hline $\operatorname{Pr}\left(h_{2} \mid e \wedge h_{1}\right)$ & .35 & .68 & .16 & .19 \\
$\operatorname{Pr}\left(h_{3} \mid e \wedge h_{1}\right)$ & .67 & .83 & .12 & .25 \\
\hline
\end{tabular}

Note. $\quad P r=$ probability; $h_{1}=$ isolated conjunct; $h_{2}=$ added conjunct (the most confirmed); $h_{3}=$ added conjunct (the most probable).

questions used, see the "Design, procedure and materials" section below and Appendix B).

\section{Method}

Participants. Participants were 180 undergraduates (105 females; mean age: 22.35 years) from the Trento University and Milan-Bicocca University.

Design, procedure, and materials. We employed a betweensubjects design. Participants were interviewed individually and randomly divided into six groups, two for each among three (probability, confirmation, and conjunction fallacy) tasks. The stimuli included four experimental scenarios (the Violinist, the Student, the Swedish girl, and the Swiss man scenarios, all provided in Appendix B), and no fillers.

The probability task was meant to compare, for each of the four scenarios, the average judged values of $\operatorname{Pr}\left(h_{2} \mid e \wedge h_{1}\right)$ and $\operatorname{Pr}\left(h_{3} \mid e \wedge h_{1}\right)$. Accordingly, we provided $e$ along with $h_{1}$ as given information, and then we asked how probable hypothesis $h_{2}$ was in light of such information. The same was done for $h_{3}$. For the sake of a fair test of diverging predictions, here and in the subsequent experiments, this control task has been performed in frequency format, as the latter seems relatively uncontroversial as a way to elicit statistical estimates. Moreover, to prevent carryover effects, we divided the participants into two groups, so that for a given scenario the same participant was presented with only one question concerning either $h_{2}$ or $h_{3}$. There being four scenarios, all participants answered (in random order) two questions regarding $h_{2}$ and two questions regarding $h_{3}$.

The confirmation task was meant to compare, for each of the four scenarios, the average judged values of $c\left(h_{2}, e \mid h_{1}\right)$ and $c\left(h_{3}, e \mid h_{1}\right)$. Accordingly, we first provided $h_{1}$ as a piece of background information and instructed the participants to consider $h_{2}$ as a hypothesis (i.e., as a statement which could be true or false). Then we provided statement $e$ as a piece of newly given evidence and asked how this new piece of information affected hypothesis $h_{2}$ compared with its prior background credibility on a scale ranging from -10 (maximally weakens) to +10 (maximally strengthens). The same was done for $h_{3}$. To prevent carryover effects, we divided the participants into two groups, so that for a given scenario the same participant was presented with only one question concerning either $h_{2}$ or $h_{3}$. There being four scenarios, all participants answered (in random order) to two questions regarding $h_{2}$ and two questions regarding $h_{3}$.

The conjunction fallacy task was meant to detect, for each of the four scenarios, the occurrence of conjunction fallacy responses and their distribution between $h_{1} \wedge h_{2}$ versus $h_{1} \wedge h_{3}$. The conjunction fallacy task was thus identical to that from Experiment 1 . As no fillers were employed, we preferred to divide participants into two groups facing two scenarios each.

\section{Results and Discussion}

The results of the probability task are displayed in Table 4. An independent-samples $t$ test revealed that judged probability was lower for $h_{2}$ than for $h_{3}$ in the Violinist and Swiss man scenarios0.35 versus $0.67, t(58)=-3.89, p<.01$, two-sided, and 0.68 versus $0.83, t(58)=-2.39, p<.05$, two-sided, respectivelywhile no significant difference emerged in the Student and Swedish girl scenarios- 0.16 versus $0.12, t(58)=0.9, n s$, two-sided, and 0.19 versus $0.25, t(58)=-1.04, n s$, two-sided, respectively)

The results of the confirmation task are displayed in Table 5. An independent-samples $t$ test revealed that judged confirmation was higher for $h_{2}$ than for $h_{3}$ in all scenarios: 5.6 versus $-0.1, t(58)=$ 7.31, $p<.01$, two-sided; 4.7 versus $-0.6, t(58)=7.40, p<.01$, two-sided; 3.9 vs. $-0.4, t(58)=5.47, p<.01$, two-sided; and 2.6 versus $-4.1, t(58)=7.16, p<.01$, two-sided, for the Violinist, Swiss man, Student, and Swedish girl scenarios, respectively).

Therefore, we can once again dissociate the effects of confirmation versus probability of the added conjunct on conjunction fallacy rates. According to our analysis, the conjunction fallacy rate attached to $h_{1} \wedge h_{2}$ should be higher than that for $h_{1} \wedge h_{3}$ in all scenarios (as judged confirmation is higher for $h_{2}$ than for $h_{3}$ ). According to the alternative accounts considered, however, a different pattern should obtain; that is, the conjunction fallacy rate attached to $h_{1} \wedge h_{2}$ should be lower than that for $h_{1} \wedge h_{3}$ in the Violinist and Swiss man scenarios (as judged probability is lower for $h_{2}$ than for $h_{3}$ ), while there should be no difference in the conjunction fallacy rates attached to $h_{1} \wedge h_{2}$ and $h_{1} \wedge h_{3}$ in the Student and Swedish girl scenario (as there is no significant difference in judged probability for $h_{2}$ and for $h_{3}$ ).

The results of the conjunction fallacy task are displayed in Table 6. A minority of participants chose the correct option $h_{1}(20 \%$, $27 \%, 26 \%$, and $40 \%$ in the Violinist, Swiss man, Student, and Swedish girl scenarios, respectively). Among the participants providing fallacious responses, a large majority chose the conjunction for which the added conjunct ranked higher in assessments of confirmation but not in judgments of probability. More precisely, the preferences for $h_{1} \wedge h_{2}$ versus $h_{1} \wedge h_{3}$ were $83 \%$ versus $17 \%$ in the Violinist scenario, $86 \%$ versus $14 \%$ in the Swiss man scenario, $77 \%$ versus $23 \%$ in the Student scenario, and $89 \%$ versus $11 \%$ in the Swedish girl scenario (all distributions are significantly different from the $50 \%$ vs. $50 \%$ chance level by one-sample binomial test, $p<.02$, two-sided). Thus, results from Experiment 2 were aligned with those from Experiment 1, lending support to our

Table 5

Average Estimates in the Confirmation Task (Experiment 2) (for Each Average $N=30$ )

\begin{tabular}{lcccc}
\hline Response & $\begin{array}{c}\text { Violinist } \\
\text { scenario }\end{array}$ & $\begin{array}{c}\text { Swiss man } \\
\text { scenario }\end{array}$ & $\begin{array}{c}\text { Student } \\
\text { scenario }\end{array}$ & $\begin{array}{c}\text { Swedish girl } \\
\text { scenario }\end{array}$ \\
\hline$c\left(h_{2}, e \mid h_{1}\right)$ & +5.6 & +4.7 & +3.9 & +2.6 \\
$c\left(h_{3}, e \mid h_{1}\right)$ & -0.1 & -0.6 & -0.4 & -4.1 \\
\hline
\end{tabular}

Note. $\quad c=$ confirmation; $h_{1}=$ isolated conjunct; $h_{2}=$ added conjunct (the most confirmed); $h_{3}=$ added conjunct (the most probable). 
Table 6

Distribution of the Participants According to Their Responses in the Conjunction Fallacy Task (Experiment 2)

\begin{tabular}{|c|c|c|c|c|c|c|c|c|c|c|c|c|}
\hline \multirow[b]{2}{*}{ Response } & \multicolumn{3}{|c|}{$\begin{array}{l}\text { Violinist scenario } \\
\quad(N=30)\end{array}$} & \multicolumn{3}{|c|}{$\begin{array}{l}\text { Swiss man scenario } \\
\qquad(N=30)\end{array}$} & \multicolumn{3}{|c|}{$\begin{array}{l}\text { Student scenario } \\
\qquad(N=30)\end{array}$} & \multicolumn{3}{|c|}{$\begin{array}{l}\text { Swedish girl scenario } \\
\qquad(N=30)\end{array}$} \\
\hline & $N$ & $\%$ & $\%$ & $N$ & $\%$ & $\%$ & $N$ & $\%$ & $\%$ & $N$ & $\%$ & $\%$ \\
\hline$h_{1}$ & 6 & 20 & & 8 & 27 & & 8 & $26 \%$ & & 12 & 40 & \\
\hline$h_{1} \wedge h_{2}$ & 20 & 67 & 83 & 19 & 63 & 86 & 17 & $57 \%$ & 77 & 16 & 53 & 89 \\
\hline$h_{1} \wedge h_{3}$ & 4 & 13 & 17 & 3 & 10 & 14 & 5 & $17 \%$ & 23 & 2 & 7 & 11 \\
\hline
\end{tabular}

Note. $\quad h_{1}=$ isolated conjunct; $h_{2}=$ added conjunct (the most confirmed); $h_{3}=$ added conjunct (the most probable).

reading of the conjunction fallacy as depending on the perceived confirmation of the added conjunct.

\section{Experiment 3}

Experiments 1 and 2 proved that the confirmation-theoretic account of the conjunction fallacy better predicts $M-A$ paradigm data compared with alternative interpretations by which the perceived probability of the added conjunct counts as the main critical variable. In Experiment 3, we examined if this result extends to the $A-B$ paradigm. As in Experiment 2, we asked for absolute confirmation and probability judgments. The $A-B$ paradigm being at issue, though, no specific item of evidence $e$ was explicitly provided at the outset (for a detailed description of the experimental questions used, see Appendix C).

\section{Method}

Participants. Participants were 200 undergraduates (98 females; mean age: 22.82 years) from the Trento University and Milan-Bicocca University.

Design, procedure, and materials. We employed a betweensubjects design. Participants were interviewed individually and randomly divided into five groups, one for the conjunction fallacy task, two each for the probability and confirmation tasks. The stimuli included three experimental scenarios (the Athlete, Surgeon, and Swiss person scenarios, all provided in Appendix C) and no fillers.

The probability task was meant to compare, for each of the three scenarios, the average judged values of $\operatorname{Pr}\left(h_{2} \mid h_{1}\right)$ and $\operatorname{Pr}\left(h_{3} \mid h_{1}\right)$. Accordingly, we provided $h_{1}$ as given information, and then we asked (in frequency format) how probable hypothesis $h_{2}$ was in light of such information. The same was done for $h_{3}$. To prevent carryover effects, we divided the participants into two groups, so that for a given scenario the same participant was presented with only one question concerning either $h_{2}$ or $h_{3}$. There being three scenarios,

Table 7

Average Estimates in the Probability Task (Experiment 3) (for Each Average $N=40$ )

\begin{tabular}{lccc}
\hline Response & $\begin{array}{c}\text { Athlete } \\
\text { scenario }\end{array}$ & $\begin{array}{c}\text { Surgeon } \\
\text { scenario }\end{array}$ & $\begin{array}{c}\text { Swiss person } \\
\text { scenario }\end{array}$ \\
\hline $\operatorname{Pr}\left(h_{2} \mid h_{1}\right)$ & .66 & .77 & .76 \\
$\operatorname{Pr}\left(h_{3} \mid h_{1}\right)$ & .59 & .78 & .75 \\
\hline
\end{tabular}

Note. $\operatorname{Pr}=$ probability; $h_{1}=$ isolated conjunct; $h_{2}=$ added conjunct (the most confirmed); $h_{3}=$ added conjunct (the most probable). participants answered (in random order) one question regarding $h_{2}$ and two questions regarding $h_{3}$, or vice versa.

The confirmation task was meant to compare, for each of the three scenarios, the average judged values of $c\left(h_{2}, h_{1}\right)$ and $c\left(h_{3}, h_{1}\right)$. Accordingly, we instructed the participants to consider $h_{2}$ as a hypothesis (i.e., as a statement which could be true or false). Then we provided statement $h_{1}$ as a piece of newly given evidence and asked how this new piece of information affected hypothesis $h_{2}$ compared with its prior background credibility on a scale ranging from -10 (maximally weakens) to +10 (maximally strengthens). The same was done for $h_{3}$. To prevent carryover effects, we divided the participants into two groups, so that for a given scenario the same participant was presented with only one question concerning either $h_{2}$ or $h_{3}$ There being three scenarios, participants answered (in random order) one question regarding $h_{2}$ and two questions regarding $h_{3}$, or vice versa.

The conjunction fallacy task was meant to detect, for each of the three scenarios, the occurrence of conjunction fallacy responses and their distribution between $h_{1} \wedge h_{2}$ versus $h_{1} \wedge h_{3}$. The conjunction fallacy task was thus identical to that from previous experiments.

\section{Results and Discussion}

The results of the probability task are displayed in Table 7. An independent-samples $t$ test did not reveal a significant difference between the judged probability of $h_{2}$ and $h_{3}$ in any of the scenarios: 0.66 versus $0.59, t(78)=1.69, n s$, two-sided; 0.77 versus 0.78 , $t(78)=-0.20, n s$, two-sided; and 0.76 versus $0.75, t(78)=0.09$, $n s$, two-sided, for the Athlete, Surgeon, and Swiss person scenarios, respectively.

The results of the confirmation task are displayed in Table 8 . An independent-samples $t$ test revealed that judged confirmation was higher for $h_{2}$ than for $h_{3}$ in all scenarios: 3.3 versus $-0.2, t(78)=$

Table 8

Average Estimates in the Confirmation Task (Experiment 3) (for Each Average $N=40$ )

\begin{tabular}{lccc}
\hline Response & $\begin{array}{c}\text { Athlete } \\
\text { scenario }\end{array}$ & $\begin{array}{c}\text { Surgeon } \\
\text { scenario }\end{array}$ & $\begin{array}{c}\text { Swiss person } \\
\text { scenario }\end{array}$ \\
\hline$c\left(h_{2}, h_{1}\right)$ & +3.3 & +2.4 & +3.1 \\
$c\left(h_{3}, h_{1}\right)$ & -0.2 & +0.2 & -0.3 \\
\hline
\end{tabular}

Note. $\quad c=$ confirmation; $h_{1}=$ isolated conjunct; $h_{2}=$ added conjunct (the most confirmed); $h_{3}=$ added conjunct (the most probable). 
Table 9

Distribution of the Participants According to Their Responses in the Conjunction Fallacy Task (Experiment 3)

\begin{tabular}{|c|c|c|c|c|c|c|c|c|c|}
\hline \multirow[b]{2}{*}{ Response } & \multicolumn{3}{|c|}{$\begin{array}{l}\text { Athlete scenario } \\
\qquad(N=40)\end{array}$} & \multicolumn{3}{|c|}{$\begin{array}{l}\text { Surgeon scenario } \\
\qquad(N=40)\end{array}$} & \multicolumn{3}{|c|}{$\begin{array}{l}\text { Swiss person scenario } \\
\quad(N=40)\end{array}$} \\
\hline & $N$ & $\%$ & $\%$ & $N$ & $\%$ & $\%$ & $N$ & $\%$ & $\%$ \\
\hline$h_{1}$ & 17 & 43 & & 18 & 45 & & 21 & 53 & \\
\hline$h_{1} \wedge h_{2}$ & 21 & 52 & 91 & 17 & 43 & 77 & 15 & 37 & 79 \\
\hline$h_{1} \wedge h_{3}$ & 2 & 5 & 9 & 5 & 12 & 23 & 4 & 10 & 21 \\
\hline
\end{tabular}

Note. $h_{1}=$ isolated conjunct; $h_{2}=$ added conjunct (the most confirmed); $h_{3}=$ added conjunct (the most probable).

7.98, $p<.01$, two-sided, for the Athlete scenario; 2.4 versus 0.2 , $t(78)=4.63, p<.01$, two-sided, for the Surgeon scenario; and 3.1 versus $-0.3, t(78)=6.17, p<.01$, two-sided, for the Swiss person scenario.

Therefore, we can once again dissociate the effects of confirmation versus probability of the added conjunct on conjunction fallacy rates. According to our analysis, the conjunction fallacy rate attached to $h_{1} \wedge h_{2}$ should be higher than that for $h_{1} \wedge h_{3}$ in all scenarios (as judged confirmation is higher for $h_{2}$ than for $h_{3}$ ). According to the alternative accounts considered, however, there should be no difference in the conjunction fallacy rates attached to $h_{1} \wedge h_{2}$ and $h_{1} \wedge h_{3}$ in any of the scenarios (as there is no significant difference in judged probability for $h_{2}$ and $h_{3}$ ).

The results of the conjunction fallacy task are displayed in Table 9. Nearly half of the participants chose the correct option $h_{1}(43 \%$, $45 \%$, and $53 \%$, in the Athlete, Surgeon, and Swiss person scenarios, respectively). Among the participants providing fallacious responses, a large majority chose the conjunction for which the added conjunct ranked higher in assessments of confirmation but not in judgments of probability. More precisely, the preferences for $h_{1} \wedge h_{2}$ vs. $h_{1} \wedge h_{3}$ were $91 \%$ vs. $9 \%$ in the Athlete scenario, $77 \%$ vs. $23 \%$ in the Surgeon scenario, and $79 \%$ vs. $21 \%$, in the Swiss person scenario (all distributions are significantly different from the $50 \%$ vs. $50 \%$ chance level by one-sample binomial test, $p<$ .02 , two-sided). Thus, results from Experiment 3 were aligned with those from Experiments 1 and 2, suggesting that the conjunction fallacy depends on the perceived confirmation of the added conjunct also in the $A-B$ paradigm.

Our stimuli were constructed to compare the effects of probability versus confirmation of the added conjunct on the occurrence of the conjunction fallacy but not to measure the impact of each of these two variables on fallacy rates across different scenarios. For one thing, stimuli were not devised to elicit a wide range of confirmation judgments associated with the same probability value. Still, as a first step for a quantitative assessment, we calculated the correlation between mean confirmation/probability judgments for the added conjuncts $h_{2}$ and $h_{3}$ and fallacy rates for the corresponding conjunctions $h_{1} \wedge h_{2}$ and $h_{1} \wedge h_{3}$ (namely, the proportion of choices in their favor out of the total number of responses in each scenario of Experiments 2 and 3). ${ }^{9}$ Confirmation of the added conjuncts was found to be strongly correlated with fallacy rate $\left(r_{s}=.89, N=14, p<.01\right.$, two-sided), while probability was not $\left(r_{s}=-.26, N=14, n s\right.$, two-sided).

Thus, results from Experiment 3 were aligned with those from Experiments 1 and 2, suggesting that the conjunction fallacy depends on the perceived confirmation of the added conjunct also in the $A-B$ paradigm.

\section{Experiment 4}

Experiments 1-3 converged in showing that the confirmationtheoretic account outperforms competing approaches in predicting the occurrence of the conjunction fallacy in a between-subjects design. In Experiment 4, we examined if this result is replicated when a within-subjects design is employed. As in Experiment 3, we asked for absolute confirmation and probability judgments as referred to scenarios belonging to the $A-B$ paradigm. Relying on a within-subjects design, we could directly connect each participant's probability and confirmation judgments with her or his response in the conjunction fallacy task. In this experimental arrangement, thus, competing accounts yielded a case-by-case prediction of the conjunction for which a fallacious judgment would occur.

\section{Method}

Participants. Participants were 63 undergraduates $(23 \mathrm{fe}-$ males; mean age: 22.14 years) from the Trento University and Milan-Bicocca University.

Design, procedure, and materials. We employed a withinsubjects design. Participants were interviewed individually and carried out all three (probability, confirmation, and conjunction fallacy) tasks. The stimuli included three experimental scenarios (the American person, Swedish person, and Swiss person scenarios, all provided in Appendix D) and three fillers, whose structure was seemingly similar to that of the experimental scenarios but with no connection to the conjunction rule (the logical form of the three hypotheses appearing in the fillers was $h_{1}, h_{2} \wedge h_{3}$, and $h_{2} \wedge h_{4}$ ).

The three tasks were identical to those of Experiment 3. All participants were given the conjunction fallacy task first, and then half of them performed the probability task followed by the confirmation task, while for the other half the order was reversed.

\footnotetext{
${ }^{9}$ While each confirmation/probability judgment is independent from all the others, preferences for the two conjunctions $\left(h_{1} \wedge h_{2}\right.$ and $\left.h_{1} \wedge h_{3}\right)$ in the same scenario are not. Therefore, the correlation analysis presented should be taken as no more than a rough indication of the relation between confirmation/probability and conjunction fallacy rates.
} 
The three experimental scenarios were presented to different participants in all their six possible different sequences. The experimental scenarios were alternated with fillers, whose position in the sequences was kept fixed, so that each of the fillers occurred before each experimental scenario the same number of times. In the probability and confirmation tasks, every scenario had to be presented twice to elicit a judgment for each of $h_{2}$ and $h_{3}$. We maximized the distance between the occurrences of the same scenario and alternated judgments for $h_{2}$ and $h_{3}$ across the various scenarios (e.g., one sequence was as follows: judgment for $h_{2}$ from the American person scenario, filler, judgment for $h_{3}$ from the Swedish person scenario, filler, judgment for $h_{2}$ from the Swiss person scenario, filler, judgment for $h_{3}$ from the American person scenario, filler, judgment for $h_{2}$ from the Swedish person scenario, filler, judgment for $h_{3}$ from the Swiss person scenario, filler).

\section{Results and Discussion}

The conjunction fallacy rates were $40 \%, 48 \%$, and $52 \%$ for the American person, Swedish person, and Swiss person scenarios, respectively. We did not count the choice of $h_{1} \wedge h_{2}\left[h_{1} \wedge h_{3}\right]$ as fallacious in the presence of probability/confirmation judgments such that $h_{2}\left[h_{3}\right]$ was seen as implied by $h_{1}$, that is, with maximal values assigned to $\operatorname{Pr}\left(h_{2} \mid h_{1}\right)\left[\operatorname{Pr}\left(h_{3} \mid h_{1}\right)\right]$ or $c\left(h_{2}, h_{1}\right)\left[c\left(h_{3}, h_{1}\right)\right]$. Overall, across the three scenarios, there were 18 cases of this kind [out of $189=63$ (participants) $\times 3$ (scenarios) responses in the conjunction fallacy task].

Experiment 4 allows for the detection of the diverging effects of the perceived confirmation versus probability of the added conjunct at the individual level. In fact, such effects can now be analyzed participant by participant rather than through the comparison of different groups. To determine whether confirmation or probability judgments better predicts which conjunction $\left(h_{1} \wedge h_{2}\right.$ vs $\left.h_{1} \wedge h_{3}\right)$ is selected when the fallacy occurs, we classified each fallacious response on the basis of the participant's probability and confirmation judgments. More specifically, the following cases were considered supportive of the confirmation account of the conjunction fallacy:

- The participant chose $h_{1} \wedge h_{2}$ and also judged $c\left(h_{2}, h_{1}\right)>c\left(h_{3}, h_{1}\right)$;

- The participant chose $h_{1} \wedge h_{3}$ and also judged $c\left(h_{2}, h_{1}\right)<c\left(h_{3}, h_{1}\right)$.

Accordingly, the following cases were considered supportive of the probability accounts of the conjunction fallacy:

- The participant chose $h_{1} \wedge h_{2}$ and also judged $\operatorname{Pr}\left(h_{2} \mid h_{1}\right)>\operatorname{Pr}\left(h_{3} \mid h_{1}\right)$;

- The participant chose $h_{1} \wedge h_{3}$ and also judged $\operatorname{Pr}\left(h_{2} \mid h_{1}\right)<\operatorname{Pr}\left(h_{3} \mid h_{1}\right)$.

Table 10 shows the complete mapping of all potential conjunction fallacy responses with respect to the competing accounts. To illustrate, a conjunction fallacy response provided by a participant for whom $c\left(h_{2}, h_{1}\right)>c\left(h_{3}, h_{1}\right)$ and $\operatorname{Pr}\left(h_{2} \mid h_{1}\right)<\operatorname{Pr}\left(h_{3} \mid h_{1}\right)$ should target $h_{1} \wedge h_{2}$ according to our confirmation account, while it should target $h_{1} \wedge h_{3}$ according to the competing approaches.

The results of the Experiment 4 are displayed in Table 11. The great majority of the fallacious responses were in line with the confirmation account of the conjunction fallacy $(80 \%, 67 \%$, and $76 \%$, in the American person, Swedish person, and Swiss person scenarios, respectively). On the other hand, only a limited proportion of the fallacious responses were in line with approaches relying on the perceived probability of the added conjunct (32\%, $30 \%$, and $55 \%$ in the American person, Swedish person, and Swiss person scenarios, respectively).

The overall pattern remains essentially unaffected if we restrictively focus on the cases in which conflicting predictions between proposals occur (i.e., Rows 1 and 3 in Table 11). Again, the majority of the fallacious responses selectively targeted the conjunction for which the added conjunct ranked higher in assessments of confirmation rather than probability. More precisely, the preferences were $77 \%$ vs. $23 \%$ in the American person scenario, $69 \%$ vs. $31 \%$ in the Swedish person scenario, and $67 \%$ vs. $33 \%$, in the Swiss person

Table 10

Classification of the Conjunction Fallacy Responses $\left(h_{1} \wedge h_{2}\right.$ and $\left.h_{1} \wedge h_{3}\right)$ Based on the Corresponding Judgments in the Probability and Confirmation Tasks (Experiment 4)

\begin{tabular}{llll}
\hline & \multicolumn{3}{c}{ Confirmation judgment } \\
\cline { 2 - 4 } Probability judgment & $c\left(h_{2}, h_{1}\right)<c\left(h_{3}, h_{1}\right)$ & $c\left(h_{2}, h_{1}\right)=c\left(h_{3}, h_{1}\right)$ & $c\left(h_{2}, h_{1}\right)>c\left(h_{3}, h_{1}\right)$ \\
\hline $\operatorname{Pr}\left(h_{2} \mid h_{1}\right)<\operatorname{Pr}\left(h_{3} \mid h_{1}\right)$ & $h_{1} \wedge h_{2}$ none & $h_{1} \wedge h_{2}$ none & $h_{1} \wedge h_{2}$ confirmation \\
& $h_{1} \wedge h_{3}$ both & $h_{1} \wedge h_{3}$ probability & $h_{1} \wedge h_{3}$ probability \\
$\operatorname{Pr}\left(h_{2} \mid h_{1}\right)=\operatorname{Pr}\left(h_{3} \mid h_{1}\right)$ & $h_{1} \wedge h_{2}$ none & $h_{1} \wedge h_{2}$ none & $h_{1} \wedge h_{2}$ confirmation \\
& $h_{1} \wedge h_{3}$ confirmation & $h_{1} \wedge h_{3}$ none & $h_{1} \wedge h_{3}$ none \\
$\operatorname{Pr}\left(h_{2} \mid h_{1}\right)>\operatorname{Pr}\left(h_{3} \mid h_{1}\right)$ & $h_{1} \wedge h_{2}$ probability & $h_{1} \wedge h_{2}$ probability & $h_{1} \wedge h_{2}$ both \\
& $h_{1} \wedge h_{3}$ confirmation & $h_{1} \wedge h_{3}$ none & $h_{1} \wedge h_{3}$ none \\
\hline
\end{tabular}

Note. The labels "confirmation"/"probability" indicate the cases that selectively support a confirmation theoretic account of the conjunction fallacy/competing approaches relying on the probability of the added conjunct. The labels "both" and "none" indicate the cases which do not disentangle the two proposals because they are either supportive or unsupportive of each. Since participants were to choose only one of the options in the conjunction fallacy task, we had to decide how to classify conjunction fallacy responses when the corresponding judgments of confirmation or probability were equal. As shown by the table, a restrictive criterion was applied, as follows: Both conjunction fallacy responses were classified as unsupportive of the confirmation account in case $c\left(h_{2}, h_{1}\right)=c\left(h_{3}, h_{1}\right)$; likewise, both conjunction fallacy responses were classified as unsupportive for the alternative approaches in case $\operatorname{Pr}\left(h_{2} \mid h_{1}\right)=\operatorname{Pr}\left(h_{3} \mid h_{1}\right)$. 
Table 11

Distribution of the Fallacious Responses in the Conjunction Fallacy Task (Experiment 4)

\begin{tabular}{|c|c|c|c|c|c|c|c|c|c|}
\hline \multirow{3}{*}{$\begin{array}{l}\text { Classification } \\
\text { Confirmation } \\
\text { Both }\end{array}$} & \multicolumn{3}{|c|}{$\begin{array}{c}\text { American person scenario } \\
\qquad(N=25)\end{array}$} & \multicolumn{3}{|c|}{$\begin{array}{c}\text { Swedish person scenario } \\
\quad(N=30)\end{array}$} & \multicolumn{3}{|c|}{$\begin{array}{l}\text { Swiss person scenario } \\
(N=33)\end{array}$} \\
\hline & $17(68 \%)$ & \multirow{3}{*}{$\begin{array}{l}\} \\
\}\end{array}$} & \multirow{3}{*}{$\begin{array}{r}20(80 \%) \\
8(32 \%)\end{array}$} & $20(67 \%)$ & \multirow{3}{*}{$\begin{array}{l}\} \\
\}\end{array}$} & \multirow{3}{*}{$\begin{array}{r}20(67 \%) \\
9(30 \%)\end{array}$} & $14(43 \%)$ & \multirow{3}{*}{$\begin{array}{l}\} \\
\}\end{array}$} & \multirow{3}{*}{$\begin{array}{l}25(76 \%) \\
18(55 \%)\end{array}$} \\
\hline & $3(12 \%)$ & & & $0(0 \%)$ & & & $11(33 \%)$ & & \\
\hline Probability & $5(20 \%)$ & & & $9(30 \%)$ & & & $7(21 \%)$ & & \\
\hline None & $0(0 \%)$ & & & $1(3 \%)$ & & & $1(3 \%)$ & & \\
\hline
\end{tabular}

Note. Responses were classified as follows: confirmation $=$ selectively supporting the confirmation theoretic account of the conjunction fallacy; probability = selectively supporting major competing approaches relying on the probability of the added conjunct; both = supporting both proposals; none = supporting none of them.

scenario (the first distribution significantly different from the $50 \%$ vs. $50 \%$ chance level; the second distribution marginally different from the $50 \%$ vs. $50 \%$ chance level; and the third distribution points in the same direction but does not reach statistical significance by onesample binomial test, $p<.05, p=.06$, and $n s$., two-sided).

For each participant, we computed an index that quantifies the difference in the number of his or her conjunction fallacies predicted by the confirmation versus alternative accounts. Such an index ranges between -3 (the participant made three conjunction fallacies that are all selectively predicted by the accounts relying of the perceived probability of the added conjunct) to 3 (the participant made three conjunction fallacies that are all selectively predicted by the confirmation-theoretic account). Zero represents the situation in which the participant made no conjunction fallacies or an equal number of conjunction fallacies in line with each of the two predictors. The distribution of the index is significantly asymmetrical in favor of the confirmation-theoretic account (onesample Wilcoxon signed rank test, $p<.01$, two-sided), and the overall sum of the index values for the 63 participants is 30 . (The same figure can be obtained from Table 11. Collapsing responses across scenarios and subtracting the conjunction fallacies in favor of the two competing accounts, one has $17+20+14=51$ minus $5+9+7=21$, i.e., 30.) This result shows that conjunction fallacies responses are better predicted by the confirmationtheoretic account than by competing accounts relying of the perceived probability of the added conjunct.

Therefore, results from Experiment 4 are fully consistent with those of previous experiments. When a within-subjects design is adopted, the conjunction fallacy still predominantly depends on the perceived confirmation of the added conjunct rather than its perceived probability.

\section{General Discussion}

Crupi et al. (2008) advocated a general framework for explaining the conjunction fallacy on the basis of confirmation relations among the conjuncts and specific evidence that is provided (or otherwise available and made salient by the scenario). Experiments 1-4 showed that the perceived degree of confirmation for the added conjunct performs better than its perceived probability as a predictor of the occurrence and prevalence of the conjunction fallacy. This result has proved consistent across different elicitation procedures for both confirmation and probability judgments (comparative vs absolute), experimental design (between- vs within-subjects), distinct classes of problems (the $M-A$ vs. $A-B$ paradigm), and varying content within each.

As pointed out earlier, most extant accounts of the conjunction fallacy consider the perceived probability of the added conjunct to be the crucial variable fostering the effect. These include proposals as diverse as weighted average (Fantino et al., 1997), configural weighted average (Nilsson et al., 2009), multiplicative combination rules with either configural (Einhorn, 1985) or simple weights (Birnbaum et al., 1990), signed summation (Yates \& Carlson, 1986), random variation (Costello, 2009), source reliability (Bovens \& Hartmann, 2003), and others besides (Busemeyer et al., 2011). Our results thus cannot be explained by these proposals and provide direct evidence for the role of inductive confirmation as a major determinant of the conjunction fallacy.

Tversky and Kahneman's (1983) original idea of representativeness deserves separate discussion. In its initial form, the representativeness reading of the conjunction fallacy was flexible enough to accommodate a number of findings, but was too fuzzy to offer clear-cut independent predictions. This being so, we concur with some critics (like Birnbaum et al., 1990, and Gigerenzer, 1996) that its explanatory scope has remained very limited. Precisely for the same reason, however, we also resist claims (see, e.g., Gavanski \& Roskov-Ewoldsen, 1991; Nilsson, 2008) that the representativeness account of the conjunction fallacy has been disproved on empirical grounds. Indeed, we argue that much of the appeal of the representativeness interpretation is retained if a confirmationtheoretic account of the conjunction fallacy is adopted. In particular, we maintain that the confirmation approach motivates a partial revival of the representativeness idea, suggesting that the latter may have been largely on the right track in its focus on the "fit" between evidence and hypotheses as the key to understanding the conjunction fallacy. In addition, this novel framework is more far-reaching than the representativeness heuristic and sufficiently well defined to allow for critical examination.

That said, we point out that the confirmation-theoretic framework has the potential to be developed as an effective descriptive account in its own terms. While much work is needed to achieve a complete model, a set of confirmation-theoretic determinants of the conjunction fallacy can be safely identified.

Firstly, our Experiments 1 and 2 clearly showed that when a specific piece of evidence $e$ is explicitly provided-as is often the case in the $M-A$ paradigm (but see below) - the prevalence of the 
conjunction fallacy is an increasing function of the perceived value of $c\left(h_{2}, e \mid h_{1}\right)$.

Moreover, Tversky and Kahneman's (1983) original results already suggested, with hindsight, that $c\left(h_{2}, e \mid h_{1}\right)$.is not the only variable involved and that confirmation relations between $h_{1}$ and $h_{2}$ can also play a critical role. A case in point concerns their character Bill in the following example: $e=$ "34 years old, intelligent but unimaginative, compulsive, and generally lifeless; when in school, strong in mathematics but weak in the humanities"; $h_{1}=$ "plays jazz for a hobby"; $h_{2}=$ "is bored by music." No conjunction fallacy effect was observed with this material (Tversky and Kahneman, 1983, p. 305). Note that here $e$ quite clearly disconfirms $h_{1}$ and confirms $h_{2}$ (much as happens with the standard Linda case). Apparently, however, this is off-set by $h_{1}$ and $h_{2}$ being "highly incompatible" (Tversky and Kahneman, 1983, p. $305)$. In our terms, $h_{2}$ would appear to be almost definitely disconfirmed (i.e., contradicted) by $h_{1}$, even if $e$ is concurrently assumed. Such an arrangement can thus cause the conjunction fallacy rate to drop to zero. Therefore, the strength of the effect can be plausibly seen as an increasing function of the perceived value of $c\left(h_{2}, h_{1} \mid e\right)$. Of course, this very same relationship receives support from our Experiments 3 and 4 in the special case in which $e$ can be assumed to be empty (i.e., in the $A-B$ paradigm). ${ }^{10}$

Finally, consider a character, Carol, who is 34 years old, very ambitious, fluent in French, German and Spanish, and interested in current political events ( $e$ now denotes Carol's description) and assume that three hypotheses about Carol are at issue: $h_{1}=$ she knits for a hobby, $h_{1}^{*}=$ she reads poetry for a hobby, and $h_{2}=$ she works as a foreign correspondent. Shafir et al. (1990) employed this material in their Experiment 1, detecting a conjunction fallacy effect with $h_{1} \wedge h_{2}$ versus $h_{1}$, that is, a large positive difference in mean judgments between $\operatorname{Pr}\left(h_{1} \wedge h_{2} \mid e\right)$ and $\operatorname{Pr}\left(h_{1} \mid e\right)$. By contrast, the corresponding difference between judgments concerning $\operatorname{Pr}\left(h_{1}{ }^{*} \wedge h_{2} \mid e\right)$ versus $\operatorname{Pr}\left(h_{1}{ }^{*} \mid e\right)$ was close to zero. From our point of view, a further confirmation-theoretic variable is being manipulated here, for quite clearly $c\left(h_{1}, e\right)<c\left(h_{1} *, e\right)$. Shafir et al.'s (1990) results thus suggest that the strength of the effect is also a decreasing function of the degree of inductive confirmation that the isolated conjunct receives.

Putting the above pieces together, the following can be usefully assumed as a basis for future work:

$$
\mathrm{CF}=f\left[-c\left(h_{1}, e\right), c\left(h_{2}, e \mid h_{1}\right), c\left(h_{2}, h_{1} \mid e\right)\right]
$$

where $\mathrm{f}$ is an increasing function and $\mathrm{CF}$ is the probability that a conjunction fallacy occurs.

In order better to appreciate the implications of Equation 13, let us first address one possible source of concern. Suppose that three tennis matches are upcoming, and consider the following forecasts of their outcomes (after the players' names, in the brackets, their Association of Tennis Professionals [ATP] rankings as of January 2012):

$$
\begin{aligned}
& h_{1}=\text { Roddick (16) beats Federer (3) } \\
& h_{2}=\text { Djokovic (1) beats Lopez (19) } \\
& h_{2}^{*}=\text { Del Potro (11) beats Nadal (2) }
\end{aligned}
$$

In line with Nilsson and Andersson's results (2010), it is plausible that a conjunction fallacy effect would arise in judgments of $\operatorname{Pr}\left(h_{1} \wedge h_{2}\right)$ vs. $\operatorname{Pr}\left(h_{1}\right)$ but not of $\operatorname{Pr}\left(h_{1} \wedge h_{2}^{*}\right)$ versus $\operatorname{Pr}\left(h_{1}\right)$, a result that averaging models capture effectively,
(Nilsson \& Andersson's, 2010 original stimuli concerned European football matches, but the difference is inconsequential for our present purposes.) Note that these matches would quite clearly be independent events, so no confirmation relationship holds between the constituents of either conjunction $h_{1} \wedge h_{2}$ or $h_{1} \wedge h_{2}^{*}$. Moreover, no specific evidence is meant to be involved in an introductory cover story. So how could Equation 13 make sense of the difference between the two cases? To clarify the issue, one first needs to realize that, on closer inspection, cases of this kind do belong to the $M-A$ paradigm, much like Tversky and Kahneman's (1983) original Wimbledon problem. When participants predicted in 1980 that in the 1981 tournament, if Borg reached the finals, he would be more likely to lose the first set but win the match $\left(h_{1} \wedge h_{2}\right)$ than to lose the first set $\left(h_{1}\right)$, they were not relying on any cover story explicitly provided by the experimenter. The effect was due, instead, to information made salient by the scenario itself while being otherwise generally accessible (i.e., that Borg was an extremely strong player and came from a streak of Wimbledon victories). In light of this crucial element, Equation 13 gets the predictions just right in the previous examples. In fact, many participants would easily retrieve some information $e$ that is generally available (say, the relevant ATP rankings) and by which $h_{2}$ is significantly confirmed while $h_{2}^{*}$ is not, so that $c\left(h_{2}, e \mid h_{1}\right) \gg c\left(h_{2}^{*}, e \mid h_{1}\right)$. Confirmed or not, relative to what, one might still want to query. Relative to an even prior on the possible outcomes of the matches, we submit. The Bayesian practice of invoking such "uninformative" priors usually needs to be motivated by plausible symmetry considerations, and it can be more or less compelling in different circumstances. Indeed, it is well known for prompting heated and recurrent debates (see Jaynes, 2003, for a survey and a defense). At least in this case, however, it makes straightforward psychological sense, because $50 \%$ would surely be the default estimate for an agent lacking the kind of evidence at issue - unable to associate any relevant information with the players' names. Thus, unless Equation 13 is applied naïvely, data such as those from Nilsson and Andersson (2010) do not lie outside the scope of a confirmation-theoretic account of the conjunction fallacy. They rather belong to the large body of results already available that fail to discriminate between confirmation and probability as determinants of the effect.

A good deal of the conjunction fallacy literature has focused on whether and how the phenomenon is modulated by several variants of the experimental task (see, e.g., Wedell \& Moro, 2008). In particular, the employment of frequency formats and estimation procedures has been reported to mitigate the conjunction fallacy in

\footnotetext{
${ }^{10}$ The relation of inductive confirmation is symmetrical, so that $e$ confirms $h$ if and only if $h$ confirms $e$. However, the measurement of confirmation is not commutative in the sense that $c\left(h_{2}, h_{1} \mid e\right)$ does not necessarily equal $c\left(h_{1}, h_{2} \mid e\right)$ (see Crupi et al., 2007, and Eells \& Fitelson, 2002). Therefore, our choice of $c\left(h_{2}, h_{1} \mid e\right)$ rather than $c\left(h_{1}, h_{2} \mid e\right)$ is not inconsequential and should be motivated. Once again, the health survey scenario serves as a useful illustration. We assume that the confirmatory impact is much stronger from $h_{1}$ (having had one or more heart attacks) to the added conjunct $h_{2}$ (being older than 55) than it is in the opposite direction. If so, $c\left(h_{2}, h_{1} \mid e\right)$ rather than $c\left(h_{1}, h_{2} \mid e\right)$ seems to be more relevant for the strong conjunction fallacy observed. (We thank an anonymous reviewer for prompting this clarification.)
} 
various studies (e.g, Fiedler, 1988; Hertwig \& Chase, 1998), while leaving it virtually untouched in others (e.g., Sloman et al., 2003, and Tentori et al., 2004). In our experiments, we adopted a traditional set-up with probability phrasing and a choice task as a default option for wider comparability with previous results and discussions. However, nothing prevents the application of our approach to different kinds of conjunction fallacy tasks. Relying on Equation 13, one would expect the same patterns of results reported here, although with possibly varying overall fallacy rates. Indeed, we would see such investigations as a natural and valuable extension of the present work.

In more general terms, Equation 13 still leaves room for much further specification. For instance, while it does neatly capture the results from each scenario in our experiments, it would need to be refined in a more precise quantitative form for the purpose of comparing results from several scenarios across which more than one factor varies, for example, both $c\left(h_{1}, e\right)$ and $c\left(h_{2}, e \mid h_{1}\right)$. Yet Equation 13 already makes it possible to get an appealing amount of theoretical unification. First, it immediately includes the $A-B$ paradigm as a special case where $e$ can be assumed to be empty, and therefore $\mathrm{CF}=f\left[c\left(h_{2}, h_{1}\right)\right]$. Second, it represents the conjunction fallacy in classical $M-A$ problems as arising from a typically negative value of $c\left(h_{1}, e\right)$ along with a positive value of $c\left(h_{2}, e \mid h_{1}\right)$, even if no contribution is brought about by $c\left(h_{2}, h_{1} \mid e\right)$, which is typically close to zero. Once Equation 13 has been defined, moreover, the principled prediction can be made that a sufficiently high value of both $c\left(h_{2}, e \mid h_{1}\right)$ and $c\left(h_{2}, h_{1} \mid e\right)$ will yield a significant conjunction fallacy rate even with a positive rather than negative value of $c\left(h_{1}, e\right)$ possibly working against the effect. Notably, this class of cases, which is left out by the traditional $M-A$ versus $A-B$ classification, is already found in the literature. Indeed, a neat demonstration of the conjunction fallacy was obtained by Tentori et al. (2004) with their Scandinavia scenario, which seems to be precisely of this sort: $e=x$ is a (randomly selected) Scandinavian individual, $h_{1}=x$ has blonde hair, and $h_{2}=x$ has blue eyes. A further relevant example comes from Feeney, Shafto, and Dunning (2007) who adapted material originally devised by Medin, Coley, Storms, and Hayes (2003). In one of their experiments, Feeney et al. (2007) employed a scenario in which $e=$ cabbage has a property $x, h_{1}=$ lettuce has a property $x$, and $h_{2}=$ spinach has a property $x$, so that all quantities $c\left(h_{1}, e\right), c\left(h_{2}, e \mid h_{1}\right), c\left(h_{2}, h_{1} \mid e\right)$ presumably have positive perceived values. In this scenario, $56 \%$ of the participants assessed $\operatorname{Pr}\left(h_{2} \wedge h_{1} \mid e\right)$ as higher than either $\operatorname{Pr}\left(h_{1} \mid e\right)$ or $\operatorname{Pr}\left(h_{2} \mid e\right)$ or both.

As we already pointed out, precedents exist for a confirmationtheoretic approach to the conjunction fallacy (Lagnado \& Shanks, 2002; Levi, 2004; Sides et al., 2002; Tenenbaum \& Griffiths, 2001) as well as some partly related work of more recent times (see Cevolani, Crupi, \& Festa, 2010; Hartmann \& Meijs, 2012; Shogenji, 2012). ${ }^{11}$ On a larger scale, moreover, interesting connections exist with recent work by Hahn and Oaksford (2007) (see also Oaksford \& Hahn, 2007). Although employing a different terminology, these authors also convincingly draw the distinction between the posterior probability and the change between prior and posterior (measured by Good's [1983] favorite confirmation measure) in discussing a range of putative fallacies. As it should be clear now, we forcefully concur about the importance of this distinction (see Rips, 2001, p. 129, footnote 1, and Lo, Sides, Rozelle, \& Osherson, 2002, p. 186, for further consonant remarks).
For an illustration concerning the assessment of arguments, consider the following:

Premise: U. is a native English speaker.

Conclusion: U. was born in the United Kingdom.

Premise: U. is a native English speaker.

Conclusion: U. was born in the summer.

If the posterior probability $\operatorname{Pr}$ (conclusion|premises) is chosen to represent argument strength (as is the case, for instance, in Heit, 2000; Kemp \& Tenenbaum, 2009; Medin et al., 2003; Sloman \& Lagnado, 2005), then on sound statistical assumptions argument $14 \mathrm{~b}$ must be taken as stronger than argument 14a. This seems highly unsatisfactory, however, because 14a clearly exhibits a positive connection between premise and conclusion which is entirely lacking in 14b. Unlike posterior probability, a formalization of the notion of Bayesian confirmation as employed in this article would neatly capture this circumstance and appropriately rank $14 \mathrm{a}$ above $14 \mathrm{~b}$ in argument strength. Of course, the implications of this distinction remain latent in case (unlike in 14a and $14 \mathrm{~b}$ ) the conclusion of arguments is kept constant (as in Corner \& Hahn, 2009). Yet this is far from being the general case in experimental research on inductive reasoning (so-called inclusion fallacy representing a prominent example; see Crupi et al., 2008, pp. 184-187, for a discussion of the latter, and Crupi \& Tentori, in press, for more on a coherent Bayesian theory of argument strength).

Rather interestingly, the conjunction fallacy is not the only domain in which people have shown sensitivity to confirmation relations while being inaccurate in probability estimates (see Lagnado \& Shanks, 2002; Tentori, Chater, \& Crupi, 2012; and Tentori et al., 2007). This remark naturally invites conjectures on the possible cognitive and environmental processes underlying these findings. According to some theorists, well-confirmed hypotheses typically exhibit an appealing trade-off between probability and informativeness (see, e.g., Huber, 2008). One might then suggest that such hypotheses have a higher probability of being stated in conversation or communication at large (as distinct from their probability of being true) and therefore be of particular interest for human reasoners. ${ }^{12}$ Alternatively, one could try to embed the psychology of inductive confirmation and argument strength within a recent framework of the distinctively argumentative nature of reasoning in society (Mercier \& Sperber, 2011). However, our favorite conjecture, while not inconsistent with the ones previously mentioned, is different. The efficiency of detecting confirmation relations might lie, we submit, in their relative stability across different environments. According to this hypothesis, assessments of inductive dependency (either positive or negative), unlike single judgments of probability, can achieve a higher

\footnotetext{
11 These latter contributions have failed to yield original empirical results so far, mostly because they rely on epistemological notions other than inductive confirmation (verisimilitude, coherence, and justification, respectively), which have not yet found reliable experimental operationalization. As for our current data, those models could accommodate them precisely to the extent that they already mimic, or can be adapted to embed, the role of confirmation.

${ }^{12}$ We thank an anonymous reviewer for raising this point. (See also related remarks in Tversky \& Kahneman, 1983, p. 312.)
} 
degree of stability as they indirectly reflect real-world causal patterns in reliable ways. To illustrate, while the probability of contracting flu can fluctuate widely across time and space, in most circumstances a fever is valuable (albeit nonconclusive, of course) evidence supporting the hypothesis that flu has been contracted.

Needless to say, the empirical basis of these suggestions remains to be explored. For the time being, the results of Experiments 1-4 allow us to conclude that when probability and confirmation are disentangled, the latter systematically prevails as a determinant of the conjunction fallacy, indicating that the inductive confirmation of the added conjunct, while disregarded by previous accounts, is actually a major determinant of the phenomenon. Also, a more general confirmationtheoretic approach to the conjunction fallacy, as outlined in the foregoing pages, offers a coherent reconstruction of otherwise juxtaposed insights from an extensive literature. Future research will tell to what extent such achievements will lead to full understanding of this cognitive fallacy and its implications for human reasoning under uncertainty.

\section{References}

Abelson, R. P., Leddo, J., \& Gross, P. H. (1987). The strength of conjunctive explanations. Personality and Social Psychology Bulletin, 13, 141155. doi:10.1177/0146167287132001

Birnbaum, M. H., Anderson, C. J., \& Hynan, L. G. (1990). Theories of bias in probability judgment. In J. P. Caverni, J. M. Fabre, \& M. Gonzalez (Eds.), Cognitive biases: Advances in psychology (Vol. 68, pp. 477499). Amsterdam, the Netherlands: North Holland/Elsevier.

Bonini, N., Tentori, K., \& Osherson, D. (2004). A different conjunction fallacy. Mind \& Language, 19, 199-210. doi:10.1111/j.14680017.2004.00254.x

Bovens, L., \& Hartmann, S. (2003). Bayesian epistemology. Oxford, England: Oxford University Press.

Busemeyer, J. R., Franco, R., Pothos, E. M., \& Trueblood, J. S. (2011). A quantum theoretical explanation for probability judgment errors. Psychological Review, 118, 193-218. doi:10.1037/a0022542

Carnap, R. (1962). Logical foundations of probability (2nd ed.). Chicago, IL: University of Chicago Press.

Cevolani, G., Crupi, V., \& Festa, R. (2010). The whole truth about Linda: Probability, verisimilitude, and a paradox of conjunction. In M. D’Agostino, F. Laudisa, G. Giorello, T. Pievani, \& C. Sinigaglia (Eds.), New essays in logic and philosophy of science (pp. 603-615). London, England: College.

Corner, A., \& Hahn, U. (2009). Evaluating science arguments: Evidence, uncertainty, and argument strength. Journal of Experimental Psychology: Applied, 15, 199-212. doi:10.1037/a0016533

Costello, F. J. (2009). How probability theory explains the conjunction fallacy. Journal of Behavioral Decision Making, 22, 213-234. doi: $10.1002 / \mathrm{bdm} .618$

Crupi, V., Festa, R., \& Buttasi, C. (2010). Towards a grammar of Bayesian confirmation. In M. Suárez, M. Dorato, \& M. Rédei (Eds.), Epistemology and methodology of science (pp. 73-93). Dordrecht, the Netherlands: Springer.

Crupi, V., Fitelson, B., \& Tentori, K. (2008). Probability, confirmation and the conjunction fallacy. Thinking \& Reasoning, 14, 182-199. doi: 10.1080/13546780701643406

Crupi, V., \& Tentori, K. (2010). Irrelevant conjunction: Statement and solution of a new paradox. Philosophy of Science, 77, 1-13. doi:10.1086/ 650205

Crupi, V., \& Tentori, K. (in press). Confirmation as partial entailment: A representation theorem in inductive logic. Journal of Applied Logic.

Crupi, V., Tentori, K., \& Gonzalez, M. (2007). On Bayesian measures of evidential support: Theoretical and empirical issues. Philosophy of Science, 74, 229-252. doi:10.1086/520779

Earman, J. (1992). Bayes or bust? Cambridge, MA: MIT Press.

Eells, E., \& Fitelson, B. (2002). Symmetries and asymmetries in evidential support. Philosophical Studies, 107, 129-142. doi:10.1023/A: 1014712013453

Einhorn, J. H. (1985). A model of the conjunction fallacy (Working paper) Chicago IL: Center for Decision Research, Graduate School of Business, University of Chicago.

Fantino, E., Kulik, J., Stolarz-Fantino, S., \& Wright, W. (1997). The conjunction fallacy: A test of averaging hypotheses. Psychonomic Bulletin \& Review, 4, 96-101.

Feeney, A., Shafto, P., \& Dunning, D. (2007). Who is susceptible to conjuncton fallacies in category-based induction? Psychonomic Bulletin \& Review, 14, 884-889. doi:10.3758/BF03194116

Festa, R. (1999). Bayesian confirmation. In M. Galavotti \& A. Pagnini (Eds.), Experience, reality, and scientific explanation (pp. 55-87). Dordrecht, the Netherlands: Kluwer.

Fiedler, K. (1988). The dependence of the conjunction fallacy on subtle linguistic factors. Psychological Research, 50, 123-129. doi:10.1007/ BF00309212

Fisher, R. A. (1922). On the mathematical foundations of theoretical statistics. Philosophical Transactions of the Royal Society of London, Series A: Mathematical, Physical, \& Engineering Sciences, 222, 309 368. doi:10.1098/rsta.1922.0009

Fisk, J. E. (2004). Conjunction fallacy. In R. F. Pohl (Ed.), Cognitive illusions: A handbook on fallacies and biases in thinking, judgment, and memory. London, England: Psychology Press.

Fitelson, B. (2005). Inductive logic. In J. Pfeifer \& S. Sarkar (eds.), Philosophy of science: An encyclopedia (pp. 384-393). New York, NY: Routledge.

Fitelson, B. (2006). Logical foundations of evidential support. Philosophy of Science, 73, 500-512. doi:10.1086/518320

Franco, R. (2009). The conjunction fallacy and interference effects. Journal of Mathematical Psychology, 53, 415-422. doi:10.1016/ j.jmp.2009.02.002

Gavanski, I., \& Roskos-Ewoldsen, D. R. (1991). Representativeness and conjoint probability. Journal of Personality and Social Psychology, 61, 181-194. doi:10.1037/0022-3514.61.2.181

Gigerenzer, G. (1996). On narrow norms and vague heuristics: A reply to Kahneman and Tversky (1996). Psychological Review, 103, 592-596. doi:10.1037/0033-295X.103.3.592

Giora, R. (2006). Anything negatives can do affirmatives can do just as well, except for some metaphors. Journal of Pragmatics, 38, 981-1014. doi:10.1016/j.pragma.2005.12.006

Good, I. J. (1968). Corroboration, explanation, evolving probability, simplicity, and a sharpened razor. British Journal for the Philosophy of Science, 19, 123-143. doi:10.1093/bjps/19.2.123

Good, I. J. (1983). Good thinking. Minneapolis: University of Minnesota Press.

Gould, S. J. (1992). Bully for brontosaurus. Further reflections in natural history (pp. 463-469). London, England: Penguin Books.

Hahn, U., \& Oaksford, M. (2007). The rationality of informal argumentation: A Bayesian approach to reasoning fallacies. Psychological Review, 114, 704-732. doi:10.1037/0033-295X.114.3.704

Hartmann, S., \& Meijs, W. (2012). Walter the banker: The conjunction fallacy reconsidered. Synthese, 184, 73-87. doi:10.1007/s11229-0099694-6

Heit, E. (2000). Properties of inductive reasoning. Psychonomic Bulletin \& Review, 7, 569-592. doi:10.3758/BF03212996

Hertwig, R., \& Chase, V. M. (1998). Many reasons or just one: How response mode affects reasoning in the conjunction problem. Thinking \& Reasoning, 4, 319-352. doi:10.1080/135467898394102

Hertwig, R., \& Gigerenzer, G. (1999). The "conjunction fallacy" revised: 
How intelligent inferences look like reasoning errors. Journal of Behavioral Decision Making, 12, 275-305. doi:10.1002/(SICI)10990771(199912)12:4<275::AID-BDM323>3.0.CO;2-M

Hintikka, J. (2004). A fallacious fallacy? Synthese, 140, 25-35. doi: 10.1023/B:SYNT.0000029938.17953.10

Horvitz, E., \& Heckerman, D. (1986). The inconsistent use of measures of certainty in artificial intelligence research. In L. N. Kanal \& J. F. Lemmer (Eds.), Uncertainty in artificial intelligence (pp. 137-151). Amsterdam, the Netherlands: North-Holland.

Huber, F. (2008). Assessing theories, Bayes style. Synthese, 161, 89-118. doi:10.1007/s11229-006-9141-x

Jarvstad, A., \& Hahn, U. (2011). Source reliability and the conjunction fallacy. Cognitive Science, 35, 682-711. doi:10.1111/j.15516709.2011.01170.x

Jaynes, E. T. (2003). Probability theory: The logic of science. Cambridge, England: Cambridge University. doi:10.1017/CBO9780511790423

Juslin, P., Nilsson, H., \& Winman, A. (2009). Probability theory, not the very guide of life. Psychological Review, 116, 856-874. doi:10.1037/ a0016979

Kahneman, D., \& Frederick, S. (2002). Representativeness revised: Attribute substitution in intuitive judgment. In T. Gilovich, D. Griffin, \& D. Kahneman (Eds.), Heuristics and biases: The psychology of intuitive judgment (pp. 49-81). New York, NY: Cambridge University Press.

Kahneman, D., \& Tversky, A. (1996). On the reality of cognitive illusions. Psychological Review, 103, 582-591. doi:10.1037/0033-295X .103.3.582

Kaup, B., Lüdtke, J., \& Zwaan, R. A. (2006). Processing negated sentences with contradictory predicates: Is a door that is not open mentally closed? Journal of Pragmatics, 38, 1033-1050. doi:10.1016/j.pragma 2005.09.012

Kemp, C., \& Tenenbaum, J. B. (2009). Structured statistical models of inductive reasoning. Psychological Review, 116, 20-58. doi:10.1037/ a0014282

Lagnado, D. A., \& Shanks, D. R. (2002). Probability judgment in hierarchical learning: A conflict between predictiveness and coherence. Cognition, 83, 81-112. doi:10.1016/S0010-0277(01)00168-8

Levi, I. (1985). Illusions about uncertainty. British Journal for Philosophy of Science, 36, 331-340. doi:10.1093/bjps/36.3.331

Levi, I. (2004). Jaakko Hintikka. Synthese, 140, 37-41. doi:10.1023/B: SYNT.0000029939.13900.04

Lo, Y., Sides, A., Rozelle, J., \& Osherson, D. (2002). Evidential diversity and premise probability in young children's inductive judgment. Cognitive Science, 26, 181-206. doi:10.1207/s15516709cog2602_2

Massaro, D. W. (1994). A pattern recognition account of decision making. Memory \& Cognition, 22, 616-627. doi:10.3758/BF03198400

Mastropasqua, T., Crupi, V., \& Tentori, K. (2010). Broadening the study of inductive reasoning: Confirmation judgments with uncertain evidence, Memory \& Cognition, 38, 941-950. doi:10.3758/MC.38.7.941

Medin, D. L., Coley, J. D., Storms, G., \& Hayes, B. K. (2003). A relevance theory of induction. Psychonomic Bulletin \& Review, 10, 517-532. doi:10.3758/BF03196515

Mercier, H., \& Sperber, D. (2011). Why do human reason? Arguments for an argumentative theory. Behavioral and Brain Sciences, 34, 57-74. doi:10.1017/S0140525X10000968

Moro, R. (2009). On the nature of the conjunction fallacy. Synthese, 171, 1-24. doi:10.1007/s11229-008-9377-8

Nilsson, H. (2008). Exploring the conjunction fallacy within a category learning framework. Journal of Behavioral Decision Making, 21, 471490. doi:10.1002/bdm.615

Nilsson, H., \& Andersson, P. (2010). Making the seemingly impossible appear possible: Effects of conjunction fallacies in evaluation of bets on football games. Journal of Economic Psychology, 31, 172-180. doi: 10.1016/j.joep.2009.07.003

Nilsson, H., Winman, A., Juslin, P., \& Hansson, G. (2009). Linda is not a bearded lady: Configural weighting and adding as the cause of extension errors. Journal of Experimental Psychology: General, 138, 517-534. doi: $10.1037 / \mathrm{a} 0017351$

Oaksford, M., \& Hahn, U. (2007). Induction, deduction, and argument strength in human reasoning and argumentation. In A. Feeney. \& E. Heit (Eds.), Inductive reasoning. experimental, developmental, and computational approaches (pp. 269-301). Cambridge, England: Cambridge University Press.

Olsson, E. J. (2005). Review of Bovens, L. \& Hartmann, S., "Bayesian Epistemology." Studia Logica, 81, 289-292.

Peijnenburg, J. (2012). Case of confusing probability and confirmation. Synthese, 184, 101-107. doi:10.1007/s11229-009-9692-8

Popper, K. R. (1954). Degree of Confirmation, British Journal for the Philosophy of Science, 5, 143-149. doi:10.1093/bjps/V.18.143

Rao, G. (2009). Probability error in diagnosis: The conjunction fallacy among beginning medical students. Family Medicine, 41, 262-265.

Rips, L. J. (2001). Two kinds of reasoning. Psychological Science, 12, 129-134. doi:10.1111/1467-9280.00322

Shafir, E. B., Smith, E. E., \& Osherson, D. N. (1990). Typicality and reasoning fallacies. Memory \& Cognition, 18, 229-239. doi:10.3758/ BF03213877

Shier, D. (2000). Can human rationality be defended a priori? Behavior and Philosophy, 28, 67-81.

Shogenji, T. (2012). The degree of epistemic justification and the conjunction fallacy. Synthese, 184, 29-48. doi:10.1007/s11229-009-9699-1

Sides, A., Osherson, D., Bonini, N., \& Viale, R. (2002). On the reality of the conjunction fallacy. Memory \& Cognition, 30, 191-198. doi: 10.3758/BF03195280

Sloman, S. A., \& Lagnado, D. (2005). The problem of induction. In R. Morrison \& K. Holyoak (Eds.), Cambridge handbook of thinking and reasoning (pp. 95-116). New York, NY: Cambridge University Press.

Sloman, S. A., Over, D., Slovak, L., \& Stibel, J. M. (2003). Frequency illusions and other fallacies. Organizational Behavior and Human Decision Processes, 91, 296-309. doi:10.1016/S0749-5978(03)00021-9

Stein, E. (1996). Without good reason: The rationality debate in philosophy and cognitive science. Oxford, England: Clarendon Press.

Stich, S. (1990). The fragmentation of reason: Preface to a pragmatic theory of cognitive evaluation. Cambridge, MA: MIT Press.

Stolarz-Fantino, S., Fantino, E., Zizzo, D. J., \& Wen, J. (2003). The conjunction fallacy: New evidence for robustness. American Journal of Psychology, 116, 15-34. doi:10.2307/1423333

Tenenbaum, J. B., \& Griffiths, T. L. (2001). The rational basis of representativeness. In J. D. Moore \& K. Stenning (Eds.), Proceedings of 23rd annual conference of the Cognitive Science Society (pp. 1036-1041). Hillsdale, NJ: Erlbaum.

Tentori, K., Bonini, N., \& Osherson, D. N. (2004). The conjunction fallacy: A misunderstanding about conjunction? Cognitive Science, 28, 467477. doi: $10.1207 / \mathrm{s} 15516709 \operatorname{cog} 2803 \_8$

Tentori, K., Chater, N., \& Crupi, V. (2012). Accuracy and test-retest reliability of probability versus confirmation judgments. Manuscript in preparation.

Tentori, K., \& Crupi, V. (2012a). How the conjunction fallacy is tied to probabilistic confirmation: Some remarks on Schupbach (2012). Synthese, 184, 3-12. doi:10.1007/s11229-009-9701-y

Tentori, K., \& Crupi, V. (2012b). On the conjunction fallacy and the meaning of and, yet again: A reply to Hertwig, Benz, and Krauss (2008). Cognition, 122, 123-134. doi:10.1016/j.cognition.2011.09.002

Tentori, K., Crupi, V., Bonini, N., \& Osherson, D. (2007). Comparison of confirmation measures. Cognition, 103, 107-119.

Tversky, A. (1977). Features of similarity. Psychological Review, 84, 327-352. doi:10.1037/0033-295X.84.4.327

Tversky, A., \& Kahneman, D. (1974, September 27). Judgment under uncertainty: Heuristics and biases. Science, 185, 1124-1131. doi: 10.1126/science.185.4157.1124 
Tversky, A., \& Kahneman, D. (1982). Judgments of and by representativeness. In D. Kahneman, P. Slovic, \& A. Tversky (Eds.), Judgment under uncertainty: Heuristics and biases (pp. 84-98). New York, NY: Cambridge University Press.

Tversky, A., \& Kahneman, D. (1983). Extensional vs. intuitive reasoning: The conjunction fallacy in probability judgment. Psychological Review, 90, 293-315.
Wedell, D. H., \& Moro, R. (2008). Testing boundary conditions for the conjunction fallacy: Effects of response mode, conceptual focus and problem type. Cognition, 107, 105-136. doi:10.1016/j.cognition.2007.08.003

Yates, J. F., \& Carlson, B. W. (1986). Conjunction errors: Evidence for multiple judgment procedures, including "signed summation." Organizational Behavior and Human Decision Processes, 37, 230-253. doi: 10.1016/0749-5978(86)90053-1

\section{Appendix A}

\section{Scenarios Employed in Experiment 1}

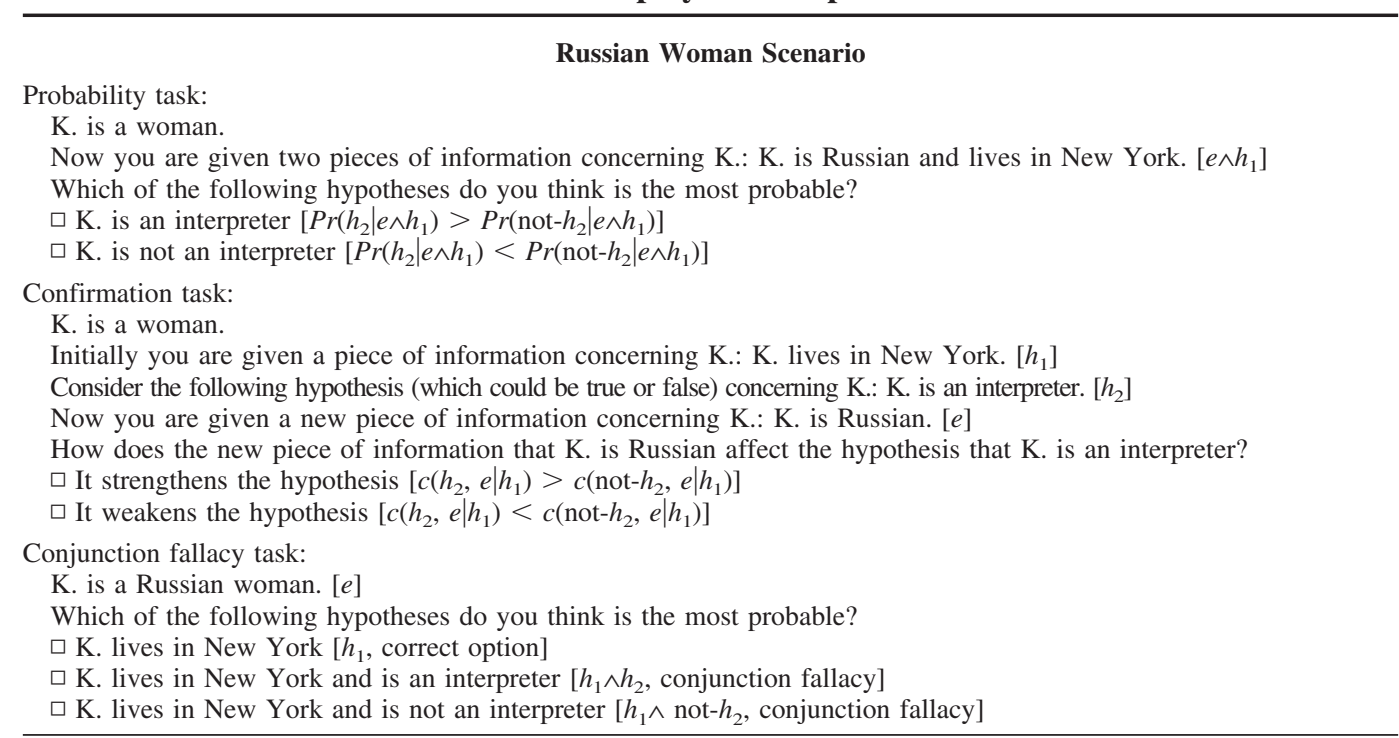

American Man Scenario

The tasks in this scenario had exactly the same structure as those described above. The critical statements were as follows:

$e=\mathrm{J}$. is an American man.

$h_{1}=$ J. speaks Italian fluently.

$h_{2}=\mathrm{J}$. is overweight.

Note. The square brackets did not appear in the original stimuli and represent the formal meaning of the sentences at issue or response options available. 


\section{Appendix B}

\section{Scenarios Employed in Experiment 2}

Probability task:

Violinist Scenario

Consider 100 people who have a degree in violin performance and are expert mountaineers. $\left[e \wedge h_{1}\right]$

$\square$ How many of them do you think give music lessons? /100. $\left[\operatorname{Pr}\left(h_{2} \mid e \wedge h_{1}\right)\right]^{*}$

$\left({ }^{*}=\right.$ for half of the participants, the question regarded $\overline{h_{3}=}$ "own an umbrella.")

Confirmation task:

O. is an expert mountaineer. $\left[h_{1}\right]$

Consider the following hypothesis (which could be true or false) concerning O.: O. gives music lessons. $\left[h_{2}\right]^{*}$

Now you are given a new piece of information concerning O.: O. has a degree in violin performance. $[e]$

How does the new piece of information that $\mathrm{O}$. has a degree in violin performance affect the hypothesis that $\mathrm{O}$. gives music lessons?

The information that $\mathrm{O}$. has a degree in violin performance

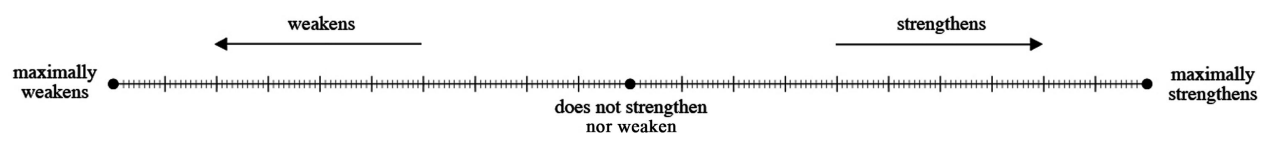

the hypothesis that $\mathrm{O}$. gives music lessons.

$\left({ }^{*}=\right.$ for half of the participants the question regarded $h_{3}=$ "owns an umbrella.")

Conjunction fallacy task:

$\mathrm{O}$. has a degree in violin performance. $[e]$

Which of the following hypotheses do you think is the most probable?

$\square \mathrm{O}$. is an expert mountaineer. [ $h_{1}$, correct option]

$\square \mathrm{O}$. is an expert mountaineer and gives music lessons. $\left[h_{1} \wedge h_{2}\right.$, conjunction fallacy]

$\square \mathrm{O}$. is an expert mountaineer and owns an umbrella. $\left[h_{1} \wedge h_{3}\right.$, conjunction fallacy]

Swiss Man Scenario

The tasks in this scenario had exactly the same structure as those described above. The critical statements were as follows:

$e=\mathrm{L}$. is a Swiss man.

$h_{1}=$ L. knows the tiramisu recipe.

$h_{2}=$ L. can ski.

$h_{3}=$ L. has a driving license.

\section{Student Scenario}

The tasks in this scenario had exactly the same structure as those described above. The critical statements were as follows:

$e=\mathrm{C}$. is an Italian undergraduate student.

$h_{1}=$ C. has red hair.

$h_{2}=$ C. in 2007 went to Barcelona under the Erasmus program.

$h_{3}=$ C. in 2007 spent his summer holidays in America.

\section{Swedish Girl Scenario}

The tasks in this scenario had exactly the same structure as those described above. The critical statements were as follows:

$e=\mathrm{A}$. is a Swedish girl.

$h_{1}=$ A. studies in Italy.

$h_{2}=$ A. works as a model.

$h_{3}=\mathrm{A}$. has brown hair.

Note. The square brackets did not appear in the original stimuli and represent the formal meaning of the sentences at issue or response options available. 


\section{Appendix C}

\section{Scenarios Employed in Experiment 3}

Probability task:

\section{Athlete Scenario}

Consider 100 people who are engaged in athletic competitions. [ $\left.h_{1}\right]$

$\square$ How many of them do you think are younger than 25 years old?

$*$ = for half of the participants the question regarded $h_{3}=$ "have brown

Confirmation task:

Consider the following hypothesis (which could be true or false) concerning a person R.: R. is younger than 25 years old. $\left[h_{2}\right]^{*}$

Now you are given a new piece of information concerning R.: R. is engaged in athletic competitions. [ $\left.h_{1}\right]$

How does the new piece of information that $R$. is engaged in athletic competitions affect the hypothesis that $R$. is younger than 25 years old?

The information that $\mathrm{R}$. is engaged in athletic competitions

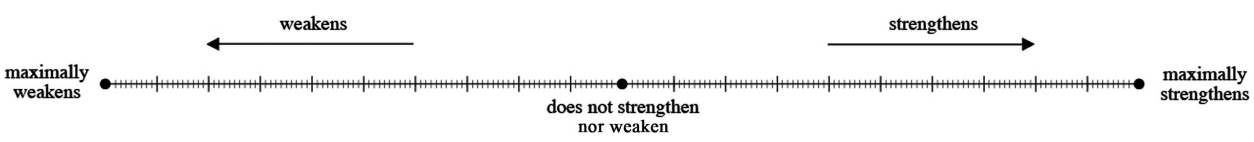

the hypothesis that $\mathrm{R}$. is younger than 25 years old.

(* $=$ for half of the participants the question regarded $h_{3}=$ "has brown hair.")

Conjunction fallacy task:

Do you think it is most probable that a person:

$\square$ is engaged in athletic competitions. [ $h_{1}$, correct option]

$\square$ is engaged in athletic competitions and is younger than 25 years old. [ $h_{1} \wedge h_{2}$, conjunction fallacy]

$\square$ is engaged in athletic competitions and has brown hair. [ $h_{1} \wedge h_{3}$, conjunction fallacy]

\section{Surgeon Scenario}

The tasks in this scenario had exactly the same structure as those described above. The critical statements were as follows:

$h_{1}=\mathrm{V}$. works as a surgeon.

$h_{2}=\mathrm{V}$. is male.

$h_{3}=\mathrm{V}$. is right-handed.

\section{Swiss Person Scenario}

The tasks in this scenario had exactly the same structure as those described above. The critical statements were as follows:

$h_{1}=$ M. is Swiss.

$h_{2}=$ M. can ski.

$h_{3}=$ M. has a driving license.

Note. The square brackets did not appear in the original stimuli and represent the formal meaning of the sentences at issue or response options available. 


\section{Appendix D}

\section{Scenarios Employed in Experiment 4}

American Person Scenario

$h_{1}=\mathrm{T}$. is American.

$h_{2}=\mathrm{T}$. is overweight.

$h_{3}=\mathrm{T}$. owns an umbrella.

\section{Swedish Person Scenario}

$h_{1}=\mathrm{U}$. is Swedish.

$h_{2}=\mathrm{U}$. has blond hair.

$h_{3}=\mathrm{U}$. owns a toothbrush.

\section{Swiss Person Scenario}

$h_{1}=\mathrm{Z}$. is Swiss

$h_{2}=$ Z. can ski.

$h_{3}=Z$. owns a swimsuit.

Note. The tasks in this experiment had exactly the same structure as those in Experiment 3; therefore, only the critical statements in each scenario are reported.

Received June 9, 2011

Revision received March 28, 2012

Accepted April 1, 2012 